\title{
The Acquisition of Auxiliary Syntax: A Longitudinal Elicitation Study. Part 2: The Modals and Auxiliary DO
}

Caroline F. Rowland University of Liverpool, Liverpool, England

Anna L. Theakston University of Manchester, Manchester, England
Purpose: The study of auxiliary acquisition is central to work on language development and has attracted theoretical work from both nativist and constructivist approaches. This study is part of a 2-part companion set that represents a unique attempt to trace the development of auxiliary syntax by using a longitudinal elicitation methodology. The aim of the research described in this part is to track the development of modal auxiliaries and auxiliary DO in questions and declaratives to provide a more complete picture of the development of the auxiliary system in English-speaking children.

Method: Twelve English-speaking children participated in 2 tasks designed to elicit auxiliaries CAN, WILL, and DOES in declaratives and yes/no questions. They completed each task 6 times in total between the ages of 2;10 (years;months) and 3;6. Results: The children's levels of correct use of the target auxiliaries differed in complex ways according to auxiliary, polarity, and sentence structure, and these relations changed over development. An analysis of the children's errors also revealed complex interactions between these factors.

Conclusions: These data cannot be explained in full by existing theories of auxiliary acquisition. Researchers working within both generativist and constructivist frameworks need to develop more detailed theories of acquisition that predict the pattern of acquisition observed.

KEY WORDS: syntax, auxiliary acquisition, preschool children

$\mathrm{T}$ his is the second of a two-part work documenting auxiliary acquisition in 2- to 3-year-old children learning English. In Part 1 (Theakston \& Rowland, this issue), we documented the acquisition of auxiliary $\mathrm{BE}^{1}$ in children aged approximately $2 ; 10$ (years;months) to $3 ; 6$ and tested the predictions of a number of theoretical accounts of auxiliary development. In that article, we reported that the children's levels of correct use of two forms of $\mathrm{BE}$ (is and are) differed according to auxiliary form and sentence structure, and these relations changed over development. For is, children showed similar levels of correct use in declaratives and yes/no and $w h$-questions, perhaps suggesting a knowledge of the relation between them. However, there were marked differences between structures for are. In declarative constructions, the children's level of performance with is and are was similar, perhaps suggesting that they were aware of the person and number relation between the forms. However, the same pattern was not observed in questions on which the children performed significantly better with is than with are. Moreover, children were more likely to make errors of

\footnotetext{
${ }^{1}$ Throughout this article, uppercase letters are used to refer to auxiliary types; for example, DO refers to all forms of DO combined. Lowercase letters are used to refer to individual forms of that auxiliary (e.g., do, does).
} 
omission in declaratives, whereas agreement errors were more common in questions, such that children produced is in place of are. We concluded that the data were problematic for all existing accounts of auxiliary acquisition.

The aim of this article is to expand on the work presented in Part 1 by tracking the development of modal auxiliaries and auxiliary DO in both questions and declaratives, in positive and negative forms, and testing further predictions of theories of auxiliary acquisition. The acquisition of auxiliary DO and the modals is particularly complex. Modal auxiliaries in declaratives occur in postsubject, utterance-internal position (e.g., "He can do it"), but in most questions (not subject $w h$-questions) they occur in presubject inverted position (e.g., "What can he do?"/"Can he eat it?"). Auxiliary DO tends to occur in its positive form only in questions, because its use in declaratives is associated with added emphasis ("She likes cake" vs. "She does like cake"). It does, however, appear in negative declaratives, often concatenated with the contracted negator n't (e.g., "He doesn't like cheese"). An added complication concerns the placement of the negator in questions, because it is grammatical to either invert both the auxiliary form and a contracted negator (e.g., "Can't you reach it?") or to leave negation within the verb phrase while inverting the auxiliary (e.g., " $\mathrm{Can}$ you not reach?"). However, it is ungrammatical to mark either the auxiliary or negation (except in rare pragmatic contexts) twice (e.g., "Can you can't reach?, "Can't you not reach?"). Finally, noninverted questions (e.g., "He's eating it?", "He is doing what?") are acceptable in some contexts as a request for clarification on a previous statement or an indication of surprise. It takes Englishspeaking children some time to master many of these rules, especially those governing question formation, with most children producing errors concurrently with correct questions for a relatively long period of time. In particular, research has suggested three things: (a) Error rates in $w h$-questions with some $w h$-words (e.g., why) may be high, (b) errors may occur with some auxiliaries more than others, and (c) negated questions might attract high rates of error. It has also been suggested that $w h$-questions display higher rates of inversion error than yes/no questions, although the picture is complicated by the fact that noninverted yes/no questions are not always counted as errors because they are permissible in certain contexts (see Ambridge, Rowland, Theakston, \& Tomasello, 2006, for a review of the literature).

A number of theories have been put forward to account for the process of auxiliary acquisition in general and, in particular, the pattern of correct use and error in children's questions. Current generativist theories of auxiliary acquisition agree that Universal Grammar (UG) plays a major role in acquisition, providing children with an understanding of abstract properties, such as case, tense, and agreement (person and number) and abstract operations (e.g., MOVE) that determine how different grammatical constructions relate to each other (e.g., subject-auxiliary inversion from declaratives to questions). However, the theories differ in how they explain the interaction of UG with language-specific knowledge and in what aspects of language-specific knowledge are thought to be problematic for the child, making very different predictions about the pattern of acquisition.

Santelmann, Berk, Austin, Somashekar, and Lust (2002) argued that, because the knowledge required to perform subject-auxiliary inversion is part of UG, auxiliaries such as modals (can, will, would) that straightforwardly follow the inversion rule should be produced error free relatively quickly in both declaratives and questions (e.g., "He can eat cake" becomes "Can he eat cake?"). However, auxiliaries that require knowledge of peculiar English-specific idiosyncrasies, such as auxiliary DO, should attract high rates of errors in questions until the children learn the English-specific rules governing their use. In the case of auxiliary DO, children must learn that although it is typically absent in declaratives (e.g., "He wants cake"), it is obligatorily present in presubject position to carry tense and agreement in questions (e.g., "Does he want cake?"). This theory predicts low error rates in declaratives with all auxiliaries and low error rates in questions with modals (neither of which require knowledge of peculiar Englishspecific rules) but high error rates in questions with auxiliary DO.

Guasti, Thornton, and Wexler (1995) suggested that children operate with an understanding of the $w h$-criterion given by UG, resulting in the correct production of positive questions. However, they argued that children initially assume that the UG neg-criterion should be satisfied clause internally (within the inflectional phrase [IP] which, though grammatical in some languages, is ungrammatical in adult English. ${ }^{2}$ This results in uninversion errors and double marking errors ("Will it won't fit?", "What you can't do?"; e.g., Hurford, 1975; Maratsos \& Kuczaj, 1978) because children need to produce an auxiliary form in clauseinternal position as the host for the contracted negator (can't, don't-argued to be the spelled-out trace of the raised auxiliary form) instead of or as well as the auxiliary in inverted position. A strong version of this theory predicts that errors (in particular, doubling and uninversion errors) should not occur at all in positive questions.

\footnotetext{
${ }^{2}$ Guasti et al. argued that constructions where negation is marked clause internally through the use of not with an inverted positive auxiliary form (e.g., "Why can you not eat chocolate?") are ungrammatical in adult English, at least for the examples they cited, for which they claimed adults "would clearly have preferred the clitic form n't" (p. 228). However, it is not clear to us as speakers of British English that this particular example is ungrammatical, and this may therefore be more an issue of dialect, suggesting that adult British English in fact allows marking of negation either in inverted position or clause internally.
} 
A weaker version that allows for other influences on question acquisition that might depress correct production overall (e.g., performance limits on production) would predict that errors should be far less frequent in positive than in negative questions.

Current constructivist researchers agree in their opposition to the existence of innate constraints such as UG but differ as to the nature of the processes underlying the acquisition of auxiliaries. Van Valin (2002) argued that illocutionary force (IF) determines whether children invert auxiliaries in questions and that IF is signaled by morphemes marking tense. IF is marked core internally in declaratives but core initially in questions through subject-auxiliary inversion. Van Valin suggested that auxiliary forms that are overtly marked for tense will be produced correctly early in development, which means that modals rather than DO should be susceptible to uninversion errors because modals are not overtly marked for tense (e.g., "Where he can go?", "The boys will jump?"). He also argued for a hierarchy within the modals such that forms that overtly encode tense opposition (can [am able] vs. could [was able]) will be inverted earlier than those that do not (will/would) and suggests that children initially may not recognize negated $n^{\prime} t$ forms as tensed.

Usage-based constructivist researchers suggest that children are acquiring a set of constructions that are thought to form the basic units of adult language (e.g., Croft, 2001; Goldberg, 1995, 2006; Langacker, 1991). These constructions are form-meaning pairings that express particular relations between semantic roles (e.g., the agent and patient in a transitive construction). The basis of children's early linguistic productions is a learned knowledge of utterance-meaning pairings based on lexically specific constructions (sometimes called low-scope frames) that are of high frequency in the input (e.g., Tomasello, 2000, 2003). For example, Rowland and Pine (2000) posited an item-based learning account of the pattern of correct use and uninversion error in one child's wh-question data, arguing that the pattern of errors should reflect differences in the use of lexical frames. Correct questions, they predicted, should be based around high-frequency frames (e.g., what do + THING PROCESS), whereas errors should occur when such frames are absent from or of low frequency in the child's input and thus unlearned. This prediction was upheld in their own data and in that of Rowland (2007), who reported that errors in the $w h$ - and yes/no questions of 10 Englishlearning children tended to occur when the children had not had the opportunity to learn a frame around which to base their question.

The theory also predicts a process of gradual, developing abstraction. Children begin with a store of separately acquired, lexically based constructions, and only gradually over the course of development are they able to recognize the relations between similar lexically based constructions and to derive the intermediate and more abstract constructions that underlie adult language use. It is thought to take considerable time for children to recognize the links between auxiliaries and between constructions, such as those between yes/no questions and declaratives, because this requires children to recognize the overlap in the different semantic roles expressed in each construction and build a link between them, either in relation to specific lexical items or, eventually, at a more abstract level. Thus, children's early utterances should pattern differently according to construction type and auxiliary identity, with generalization, as evidenced by similar patterns of correct use over different auxiliaries and constructions, emerging only after a significant amount of lexical learning. Finally, the theory predicts that children rely on well-known, high-frequency utterance-initial auxiliaries when they make errors and should show a tendency to substitute high-frequency forms for lower frequency forms. This prediction has been upheld by research into the acquisition of verb argument structure and complex sentences, which suggests that children frequently substitute high-frequency lexical forms with which they are familiar for lower frequency forms in elicited production and imitation tasks (Akhtar, 1999; Kidd, Lieven, \& Tomasello, 2006; Matthews, Lieven, Theakston, \& Tomasello, 2005).

In Part 1 (Theakston \& Rowland, this issue), we argued that the proliferation of theories of auxiliary acquisition, all making very different, sometimes contradictory, predictions, is due in part to the fact that many of the studies are piecemeal-investigating only one auxiliary type, one construction type, or one error type. We also argued that much of the data on which current theories are based have been collected from children in natural conversations with caregivers or from elicitation studies conducted cross-sectionally, in which children may not produce enough examples of all the target utterances for robust analyses. Finally, all of the theoretical approaches predict some degree of lexical learning and thus logically must predict changes over time. This means that we require longitudinal data to establish more precisely the pattern of acquisition and to test their predictions. Although a number of longitudinal studies of naturalistic data have been carried out (e.g., Fletcher, 1985; Richards, 1990; Stromswold, 1990; Theakston, Lieven, Pine, \& Rowland, 2005), these often fail to capture many of the errors children produce because of sampling restrictions or limitations on the age range of the children studied and may miss errors with low-frequency items (Rowland \& Fletcher, 2005; Tomasello $\&$ Stahl, 2004).

This article, together with its companion, Part 1, fills some of the gaps in our knowledge of auxiliary acquisition by providing a comprehensive, longitudinal 
description of the acquisition of the auxiliary system by 12 English-learning children between the ages of $2 ; 10$ and 3;6. In Part 1, we investigated the acquisition of auxiliary $\mathrm{BE}$ in questions and declaratives. In this article, we focus on the modals CAN and WILL and the auxiliary DOES in positive and negative forms and in declaratives and yes/no questions. We focus on yes/no rather than $w h$-questions because these have been less intensively studied in the literature, yet they are affected by many of the same constraints (and are relevant to many of the same theories; see Ambridge et al., 2006, for a review). The children completed two tasks designed to elicit the modals CAN and WILL and third person singular (3S) auxiliary DO (DOES: does and doesn't) in positive and negative declaratives and yes/no questions. Each task (with varied items) was administered six times over the course of the study at regular intervals to allow us to determine how auxiliary use changed over development. To our knowledge, this is one of only two attempts to use longitudinal elicitation methodology to examine the acquisition of auxiliary syntax, and it provides a unique insight into the process of acquisition (see also Richards, 1990).

The two objectives of this study were (a) to determine the extent to which the children were able to demonstrate knowledge of how to use the auxiliaries CAN, WILL, and DOES in two constructions (declaratives and yes/no questions) and (b) to examine the kinds of errors that children make in the context of the theoretical accounts outlined earlier. The following were our specific aims:

1. To test whether there is any evidence that children recognize the individual auxiliaries as examples of the abstract category AUX as evidenced by the following:

a. Similar patterns of use of an auxiliary (CAN, WILL, or DOES) across two constructions (declaratives and questions)

b. Similar patterns of use across auxiliaries (CAN, WILL, and DOES) within a construction

2. To test whether children understand the relation between positive and negative forms of CAN, WILL, and DOES and whether this holds for both declaratives and questions as evidenced by similar patterns of use.

3. To test the following predictions about auxiliary use from current theories:

a. Santelmann et al. (2002). Error rates with modals should be similar in declaratives and questions. Error rates in questions with modals should be lower than in questions with DOES.

b. Van Valin (2002). In questions, negative auxiliaries will not initially be recognized as tensed and thus not placed utterance initially. Thus, error rates in negative questions will be higher than those in positive questions (especially uninversion and double marking errors). Error rates in questions with modals should be higher than in those with DOES, and error rates in questions with WILL should be higher than in questions with CAN.

c. Guasti et al. (1995). Errors in questions, and in particular auxiliary doubling and uninversion errors, should occur more with negative than positive forms.

d. Usage-based account. We did not specifically aim to test predictions regarding the role of lowscope frames (e.g., "Can you X?") in the production of correct questions because the elicitation tasks all contained full noun phrase subjects, thus reducing the likelihood that children could rely on specific high-frequency aux + subj combinations in production. However, we tested three other constructivist predictions:

i. That children's errors will pattern differently according to construction (declarative/ question) and auxiliary identity (can, can't, will, won't, does, doesn't)

ii. That children learn high-frequency auxiliaries in specific constructions earlier than those that occur with lower frequency in the input

iii. That children rely on well-known, highfrequency utterance-initial auxiliaries when they make errors in questions with CAN, WILL, and DOES and will thus show a tendency to substitute high-frequency forms for lower frequency forms.

\section{$\overline{\text { Method }}$ Participants}

Twelve children ( 7 girls and 5 boys) were recruited. The children and parents involved were all volunteers from the Manchester and Liverpool areas of the United Kingdom. The children were all within the normal range for language development, as measured by the MacArthur Communicative Development Inventory (Fenson et al., 1993) and the Clinical Evaluation of Language Fundamentals-Preschool UK Edition (Wiig, Secord, \& Semel, 2000). Full details of the recruitment and screening procedures are given in Part 1 (Theakston \& Rowland, this issue). The 12 children were approximately $2 ; 10$ at the beginning of the study (range: $2 ; 8.26-2 ; 11.07$ ), with mean lengths of utterance (MLUs) ranging between 2.59 and 
3.79 , and were approximately $3 ; 6$ at the end of the study (range: 3;4.03-3;7.04), with MLUs ranging from 2.94 to 4.40 .

\section{Procedure}

The children took part in two games designed to elicit positive and negative forms of auxiliary DOES and the modals CAN and WILL in declaratives (Game 1) and questions (Game 2). In each game, we elicited 18 different utterances with 18 different main verbs (e.g., move, kiss, paint, etc.). Each verb was elicited in both declaratives and questions, but we varied the pairing of verbs with auxiliaries and objects across games and across sessions to ensure that the children did not learn to associate a given object with a given verb or sentence type.

Each child completed the games once every 6 weeks throughout the study, resulting in six data points for each child for each game. The games were almost always conducted on different days and were on different days than the games described in Part 1 (Theakston \& Rowland, this issue). We aimed for a 4 -week break between each data point for the two games, although this sometimes varied if the family had other commitments (e.g., Week 1: declaratives game; Week 2: questions game, 4-week break; Week 6: questions game; Week 7: declarative game, 4-week break; etc.). During the 4-week break, the experimenter carried out the experimental tasks detailed in Part 1 of this companion set. To minimize the possibility of carryover effects (either within a task or between tasks), we counterbalanced the order in which children completed the games both across children and across test sessions, and the order in which the children completed the test items within each game was randomized and was different in each session (see Appendix A for a sample script showing the procedure for each of the tasks). Appendix A in Part 1 provides details of the timing of task administration.

At each of the six test sessions, each target auxiliary form was elicited three times. To ensure that we had sufficient data to allow meaningful analysis, we combined data across each pair of test sessions, resulting in three data points from the six test sessions for each game. This meant that there were six opportunities for the children to produce each of the target auxiliary forms at each data point. Each of the three data points spanned approximately 12 weeks and corresponded to the mean ages of $2 ; 11,3 ; 2$, and $3 ; 5$.

Declaratives game. There were two sets of pictures: One depicted activities taking place successfully, and the other depicted the same activities but that, for various reasons, could not be completed (e.g., one picture contained an animal hitting the ball with a bat, the second picture had the same animal and a ball but the bat was missing). The first set of pictures could be described using positive forms of CAN, WILL, and DOES (either $3 \mathrm{~S}$ ending or does, which is used for emphasis and is appropriate in the context of the game; e.g., "In my picture the boy does have an ice cream"), and the second set could be described using the corresponding negative forms. Children took part in a warm-up task with pictures that could be described using the auxiliaries BE and HAVE. The experimenter looked at her picture and described it (e.g., "In my picture the boy has got an ice cream"). She then showed the child the corresponding negative picture and asked the child to describe it (e.g., "But in your picture ..." " and the target would be "the boy hasn't got an ice cream"). This procedure was repeated for four pictures. Then the test items began. There were 18 test items in total, comprising 3 for each of DOES, CAN, and WILL in both positive and negative forms. The children were given three opportunities to provide an appropriate response. Inappropriate responses and responses that included a nontarget auxiliary were followed up with a prompt for a further response. On the fourth attempt, the experimenter modeled the target response and asked the child to imitate, to ensure that he or she understood the game.

Questions game. To set up the appropriate pragmatic context and to encourage the children to ask rather than answer questions, we used a question game format that has proved successful in previous work (see Ambridge et al., 2006; Ambridge \& Rowland, 2009). In this task, children were introduced to a toy Piglet doll and a talking horse, Dobbin. The experimenter explained that Piglet liked to play but that he was very shy and would play only where the child could not see him. Children were told that Piglet did not mind Dobbin watching him play, so the children would have to ask Dobbin questions to find out what Piglet was doing. Because Dobbin will talk only to children, and not to grown-ups, the child would have to ask the question.

First, the experimenter placed Piglet behind a screen, visible to Dobbin but not to the experimenter and the child. The experimenter then gave Piglet selected objects to play with (e.g., a bicycle) and then made a comment on what she thought Piglet would do using a declarative sentence containing the target auxiliary form; for example, for won't she said "I think Piglet won't ride the bike." The auxiliary form modeled was pragmatically appropriate for the forthcoming action (will = Piglet assented to do an action, won't $=$ Piglet refused to do an action, can = Piglet is able to do the action, can't $=$ Piglet is unable to do the action, does = Piglet carries out the action, doesn't $=$ Piglet does not carry out the action). The experimenter then prompted the child to ask Dobbin whether Piglet won't ride the bike, again modeling the target auxiliary form. Once the child had asked an appropriate question, Dobbin answered (e.g., "No, Piglet won't ride the bike"), and the screen was raised; the experimenter then made Piglet act out refusing to ride 
the bike (e.g., shaking his head and pointing to the bike).

There were four warm-up items in which children were shown how to ask questions using auxiliaries BE and HAVE. For example, Piglet was placed behind a screen with a doctor. The experimenter said "Oh no; somebody is kissing Piglet. I think it's the doctor. Ask Dobbin if the doctor is kissing Piglet." If the child asked a question, Dobbin answered with a prerecorded response. If children were unable to ask a question, the experimenter modeled the target response for them and asked them to imitate. Children then completed the 18 test questions. They were given three opportunities to provide an appropriate response. Inappropriate responses and those that included a nontarget auxiliary were followed up with a prompt for a further response, as were responses with declarative word order. If the child failed to provide an acceptable response, the experimenter modeled the correct question for the child and asked him or her to imitate (e.g., "You have to say "Will Piglet ride the bike?"').

\section{Coding}

The children's nonimitative responses were coded as target or nontarget responses. Target responses were clear attempts to provide a declarative (Game 1 ) or question (Game 2) that was appropriate in the context. Elliptical utterances in which the verb was omitted were acceptable as long as the subject was produced (e.g., "He can't"), and declaratives (but not questions) in which the subject was omitted were accepted as long as the auxiliary and verb were produced (e.g., "can't ride a bike"). In the case of negatives, if the child produced no or not without the target auxiliary, this was accepted as an appropriate target response (e.g., "He no/not ride a bike"). Similarly, the use of 3S main verb forms in place of DOES was accepted because these are grammatically acceptable sentences in the context ("He drives the car" is as acceptable as "He does drive the car"). As a reviewer pointed out, these utterances do not tell us whether the child can use the correct form of does, so in principle their inclusion in the number of scorable responses as correct questions may inflate the proportion of correct declaratives with does. However, in practice, only six of the scorable responses contained an inflected lexical verb in the place of does, so removing them from the analysis does not change the pattern or implications of the results.

Nontarget utterances were responses that were not attempts at providing an appropriate response, for example, comments about the games, production of a declarative when a question was required, no response, and so on. Nontarget responses were excluded from the analyses.

Target declarative and question responses were coded as correct or incorrect, and the nature of any errors was recorded (see Appendix B for the inclusion criteria and criteria for correct and error responses). Errors were further subdivided into auxiliary substitution errors, auxiliary omission errors, uninversion errors (questions only), double marking errors, and agreement errors. Auxiliary substitution errors were errors in which the child substituted a nontarget auxiliary for the target one (e.g., "Piglet can ride the bike" instead of "Piglet will ride the bike"). Omission errors were errors in which children omitted an auxiliary and did not provide a tensed main verb form (e.g., "Piglet ride the bike"). In questions, omission errors had to have question intonation in order to be included as a target form (e.g., "Piglet ride the bike?"). Uninversion errors were possible only in questions and occurred when the children produced a sentence with declarative word order and question intonation (e.g., "Piglet can ride the bike?", "Piglet rides the bike?"). Although these are grammatically correct in some contexts (to request clarification or express surprise), they are not correct within the context of this game. Double marking errors occurred when tense and agreement were marked twice, either by the use of two auxiliaries (e.g., "Can Piglet can't ride the bike?") or a tensed verb and an auxiliary (e.g., "Piglet can rides the bike"/"Can Piglet rides the bike?"). Agreement errors occurred when the child produced a nonagreeing verb form (e.g., "Piglet don't like the cake").

On occasions when the experimenter was unclear whether the child's response was a target response and had therefore prompted the child to respond again, only the first response that met our criteria for inclusion was coded.

In questions, the target auxiliary was determined by the form modeled by the experimenter in a declarative, whereas in declaratives the target was determined by the form modeled by the experimenter and the context of the picture shown to the child (i.e., requiring a form of opposite polarity). A particular issue arose in the coding of responses produced during the questions game. We found that six of the children produced what appeared to be double marking errors with utterance-initial is with the target auxiliary occurring in utterance-internal position (e.g., "Is Piglet can't ride a horse?"). We were concerned that these questions might be instances of the child repeating the prompt used by the experimenter and that these were actually instances of phrases such as "If Piglet can't ride the horse" (from the prompt "Ask Dobbin if Piglet can't ride the horse"). We therefore asked the children's mothers to listen to the recordings and indicate what they thought their child had said. Utterances were coded as double marked questions with a form of is only in two instances: (a) if the mother indicated that the child had said is and not if, and (b) if the utterance had rising intonation, indicating that the child was asking a question. Further evidence that children were genuinely producing double marked questions 
with is comes from the fact that the children produced these questions on occasions when they also substituted another auxiliary form for the target in utteranceinternal position, showing that they were not simply repeating the experimenter's prompt. It is also possible that the use of is in the practice items encouraged children to produce this error (i.e., a priming effect); nevertheless, these questions represent a genuine grammatical error on the part of the child rather than an imitation of a prior adult utterance.

The research assistants who collected the data transcribed the children's responses from the audio recordings. They then entered these responses into spreadsheets and coded them according to the authors' coding scheme. At the transcription stage, two complete tasks for each child were checked by one of the authors to ensure that the transcription was accurate. In cases where there was disagreement, a third person was asked to listen to the recording and indicate what was said, and the majority decision was accepted. At the coding stage, each of the authors was responsible for coding half of the data. The coding was then checked by the other author, and any disagreements were resolved through discussion.

\section{$\overline{\text { Results }}$ \\ Number of Attempts at Target}

The initial results showed that children were more likely to produce a target response for declaratives than for questions (maximum score $=6 ; M$ declaratives $=5.10$, $S E=0.28 ; M$ questions $=3.44, S E=0.49), F(1,11)=12.97$, $p=.0004, \eta^{2}=.54$. This difference was particularly prominent at $2 ; 11$, when the children produced on average 4.31 target declaratives $(S E=0.38)$ and only 2.43 target questions ( $S E=0.46$ ). At $3 ; 2$ and $3 ; 5$, the children were producing more target responses for questions $(M \mathrm{~s}=$ 3.88 and 4.03, respectively; $S E \mathrm{~S}=0.57$ and 0.57 ) but were producing even more target declarative responses $(M \mathrm{~s}=5.44$ and 5.54, respectively; $S E \mathrm{~s}=0.23$ and 0.30$)$.

There was also an effect of age: The children produced more target responses as they got older $(M 2 ; 11=$ $3.37, S E=0.29 ; M 3 ; 2=4.66, S E=0.33 ; M 3 ; 5=4.79$, $S E=0.39), F(2,22)=47.53, p<.001, \eta^{2}=.81$. To control for these effects, we conducted the analyses on the proportion of correct responses for each auxiliary in each construction as a function of the total number of target responses provided by the child for that form in that construction at each developmental point.

\section{Proportion of Correct Responses}

The percentage correct use of CAN, WILL, and DOES in declaratives and questions at each age is shown in Table 1. At all ages, the children were producing a higher proportion of correct utterances in declaratives than in questions. Three-way 2 (construction) $\times 3$ (auxiliary) $\times$ 2 (polarity) analyses of variance (ANOVAs) revealed significant main effects of structure at all ages: $2 ; 11 F(1,7)=$ $30.03, p=.001, \eta^{2}=.81 ; 3 ; 2 F(1,9)=22.10, p=.001, \eta^{2}=$ $.71 ; 3 ; 5 F(1,8)=5.81, p=.042, \eta^{2}=.42 .{ }^{3}$ Construction interacted with polarity at $2 ; 11, F(1,7)=7.79, p=.008$, $\eta^{2}=.81$, indicating that polarity had a bigger effect in questions than in declaratives. There was a marginally significant interaction among construction, auxiliary, and polarity at $3 ; 2, F(2,18)=3.30, p=.059, \eta^{2}=.27$, providing some evidence that children's errors patterned differently according to both construction and auxiliary identity, as predicted by the constructivist approach. However, there were no interactions at $3 ; 5$, suggesting that the effects of auxiliary and polarity were similar across constructions by this age. We conducted post hoc tests to determine whether there was evidence for generalization of knowledge between constructions for any of the three auxiliaries in either positive or negative form (Aim 1a). The only form for which children performed equally well in both declaratives and questions was can at $3 ; 2(p=.60$; doesn't was marginally significant at $p=.07$; all other $p \mathrm{~s}<.05$ ). Thus, the children's knowledge of how to use an auxiliary in a declarative did not allow them to produce comparable levels of correct use with that auxiliary in questions, even when the auxiliary was a modal (CAN or WILL), contrary to the prediction of Santelmann et al. (2002; Aim 3a, this article).

We analyzed the data for questions and declaratives separately in a series of ANOVAs to investigate further the interactions among construction, auxiliary, and polarity and to test the predictions of the specific theories. To compensate for the number of tests, the significant $p$ value was set at .02 for all main tests and .05 for post hoc tests that already carried Bonferroni adjustments. In all of the analyses, arcsine (square root) transformations were applied to the data.

Declaratives: Analyses across age. A 3 (age) $\times 3$ (auxiliary: CAN, WILL, DOES) $\times 2$ (polarity: positive or negative) repeated measures ANOVA revealed a main effect of age, $F(2,20)=4.80, p=.02, \eta^{2}=.32$, with children showing a significant improvement in performance between $2 ; 11$ and $3 ; 5(p=.024)$. There was also a main effect of auxiliary, $F(2,20)=6.95, p=.005, \eta^{2}=.41$; CAN was produced correctly significantly more often than DOES $(p=.005)$. There were no other effects. It is worth noting that all but six of the correct responses provided by the children with the positive form of DOES explicitly contained the auxiliary does (e.g., "My bird does throw the racket"), which was entirely appropriate within the context of the game.

\footnotetext{
${ }^{3}$ In all analyses with multiple levels of a within-subject variable, Mauchley's test for sphericity was applied, but it was not necessary to apply any corrections to the data.
} 
Table 1. Mean percentage correct use in declaratives and questions with each auxiliary form, and number of correct utterances produced.

\begin{tabular}{|c|c|c|c|c|c|c|}
\hline \multirow[b]{2}{*}{ Target auxiliary } & \multicolumn{3}{|c|}{ Declaratives } & \multicolumn{3}{|c|}{ Questions } \\
\hline & $2 ; 11^{a}$ & $3 ; 2^{a}$ & $3 ; 5^{a}$ & $2 ; 11^{a}$ & $3 ; 2^{a}$ & $3 ; 5^{\mathrm{a}}$ \\
\hline Can & $81.00(22.32)$ & $66.42(30.02)$ & 93.00 (15.05) & $41.11(40.72)$ & 61.73 (36.95) & $82.33(33.80)$ \\
\hline Can't & $79.42(25.05)$ & $68.58(32.92)$ & $82.42(17.51)$ & $13.00(23.09)$ & 40.91 (43.07) & $55.00(37.90)$ \\
\hline CAN & $80.21(23.22)$ & $67.50(28.10)$ & 87.71 (16.85) & $25.65(34.42)$ & 48.57 (38.19) & $69.91(37.53)$ \\
\hline No. correct & 73 & 86 & 104 & 20 & 47 & 71 \\
\hline Will & 48.00 (35.71) & $74.08(28.10)$ & $69.67(31.90)$ & $30.00(42.92)$ & 40.91 (43.07) & $67.17(35.49)$ \\
\hline Won't & $62.09(36.82)$ & $70.08(31.68)$ & $73.58(27.26)$ & $3.30(10.44)$ & $26.60(28.19)$ & $38.82(40.08)$ \\
\hline WILL & $54.74(36.14)$ & $72.08(29.66)$ & $71.63(29.08)$ & $16.65(33.34)$ & $34.10(36.59)$ & $53.61(39.62)$ \\
\hline No. correct & 57 & 97 & 95 & 12 & 33 & 57 \\
\hline 3S/does & 49.83 (27.09) & $63.00(27.68)$ & $61.00(39.06)$ & 27.88 (19.72) & $29.58(35.83)$ & $38.55(40.91)$ \\
\hline Doesn't & 35.58 (33.77) & $58.17(28.75)$ & $61.83(34.21)$ & $0.00(0.00)$ & $35.60(40.01)$ & $34.80(42.43)$ \\
\hline DOES & $42.71(30.81)$ & 60.58 (27.71) & $61.42(35.81)$ & 12.39 (19.06) & $32.32(36.98)$ & $36.76(40.63)$ \\
\hline No. correct & 58 & 84 & 98 & 9 & 37 & 37 \\
\hline Overall $M$ & $59.28(33.92)$ & $66.72(29.30)$ & $73.58(30.04)$ & $18.43(30.08)$ & 38.23 (37.38) & $53.68(40.94)$ \\
\hline
\end{tabular}

Note. Numbers in parentheses are standard deviations.

${ }^{a}$ Age is represented as years;months.

Declaratives: Analyses within age groups. We analyzed data from each age group in a series of 3 (auxiliary) $x$ 2 (polarity) repeated measures ANOVAs. At 2;11, the children performed best with can $(M=81.0 \%)$ and can't $(M=79.4 \%)$, followed by won't $(M=62.1 \%)$, and they performed markedly worse with will $(M=48.0 \%)$, does/3S $(M=49.8 \%)$, and doesn't $(M=35.6 \%)$. The ANOVA showed a main effect of auxiliary, $F(2,20)=5.37, p=.01$, $\eta^{2}=.35$, and a significant interaction between auxiliary and polarity, $F(2,20)=4.75, p=.02, \eta^{2}=.32$. Pairwise comparisons revealed that the children produced more correct responses with CAN than with DOES, regardless of polarity (positive forms $p=.045$, negative forms $p=.017$ ) and that they produced marginally more correct responses with the positive form does than the negative form doesn't ( $p=.05$ ).

At $3 ; 2$, performance on WILL and DOES had improved, and the ANOVA showed that there was no effect of auxiliary, $F(2,22)=0.78, p>.05, \eta^{2}=.07$, or of polarity, $F(1,11)=0.13, p>.05, \eta^{2}=.01$, and that there was no interaction between the variables, $F(2,22)=0.41, p>.05$, $\eta^{2}=.04$.

At $3 ; 5$, performance on CAN had improved, and the ANOVA showed a main effect of auxiliary, $F(2,22)=4.78$, $p=.02, \eta^{2}=.30$, but no effect of polarity, $F(1,11)=0.42$, $p>.05, \eta^{2}=.04$, and no interaction between the variables, $F(2,22)=1.24, p>.05, \eta^{2}=.10$. The children produced more correct responses with CAN than with DOES $(p=.01)$ and more correct responses with CAN than with WILL $(p=.02)$.
Declarative summary. Overall, the children's performance improved steadily, although not substantially, with age. The children were consistently performing better with CAN than with DOES (though this difference reached significance only at $2 ; 11$ and $3 ; 5$ ) and performed better with CAN than WILL at $3 ; 5$. Thus, there was little evidence that the children's knowledge of how to use CAN in declaratives generalized to WILL and DOES (Aim 1b); however, there were almost no polarity effects at all across any age (except a tendency for better performance with does than doesn't at 2;11), suggesting that the children did understand the relation between positive and negative forms of the auxiliaries in declaratives, as evidenced by similar patterns of use (Aim 2).

Questions: Analyses across age. A 3 (age) $\times 3$ (auxiliary) $\times 2$ (polarity) repeated measures ANOVA revealed a significant main effect of age, $F(2,12)=6.20$, $p=.01, \eta^{2}=.51$, with post hoc tests showing a significant improvement between $2 ; 11$ and $3 ; 5(p=.01)$ and between $3 ; 2$ and $3 ; 5(p=.046)$. There was also a main effect of auxiliary, $F(2,12)=9.22, p=.004, \eta^{2}=.61$ : CAN was produced correctly significantly more often than WILL $(p=.02)$ and DOES $(p=.01)$. There were no other effects.

Questions: Analyses within age groups. At 2;11, there was a clear main effect of polarity, with all three positive forms correct significantly more often than all three negative forms, $F(1,7)=18.33, p=.004, \eta^{2}=.72$. There was no effect of auxiliary and no interaction between auxiliary and polarity. 
The results at $3 ; 2$ showed a marginally significant main effect of auxiliary, $F(2,18)=3.79, p=.042, \eta^{2}=$ .30 , and an interaction between auxiliary and polarity, $F(2,18)=6.32, p=.008, \eta^{2}=.41$, but no main effect of polarity, $F(1,9)=1.18, p>.05, \eta^{2}=.12$. Pairwise comparisons revealed that the children produced significantly more correct questions with can than with does ( $p=.001)$ and than with will ( $p=.046)$. There was no difference between the auxiliaries in the children's correct use of negative forms. There was a marginally significant effect of polarity for CAN ( $p=.058$, not adjusted), with children producing more correct questions with the positive form can. Although the children produced more correct questions with the positive will than the negative won't, this different was not significant. Does was produced correctly slightly less often than doesn't, but again this difference was not significant.

At $3 ; 5$, there was a main effect of auxiliary, $F(2,16)=$ $8.81, p=.003, \eta^{2}=.52$, but no effect of polarity, $F(1,8)=$ $3.22, p>.05, \eta^{2}=.29$, and this time no interaction between the variables, $F(2,16)=0.70, p>.05, \eta^{2}=.08$. The children produced significantly fewer correct responses with DOES than with CAN ( $p=.013)$ or WILL $(p=.014)$.

Questions summary. Overall, the children's performance improved steadily with age. At 2;11, performance with positive questions was significantly better than with negative questions, suggesting that children had problems placing auxiliaries in the correct utteranceinitial position and that knowledge of how to place the positive auxiliary did not generalize to the negative form (Aim 2). This effect had been predicted by both Guasti et al. (1995) and Van Valin (2002); however, the difference quickly disappeared. At 3;2, performance with can was significantly better than performance with can't, but there were no other significant polarity effects. At age $3 ; 5$, there were no polarity effects.

In terms of auxiliary effects (Aim 1b), there was a tendency for the modals to outperform DOES. This was predicted by Santelmann et al. (2002) but is contrary to the predictions of Van Valin (2002). There was also a tendency for CAN to outperform WILL (predicted by Van Valin, 2002). At 2;11, there were no auxiliary effects, but at $3 ; 2$, the children produced significantly more correct questions with $c a n$ than with does $(p=.006)$, although there were no significant differences between can't and doesn't. At 3;5, CAN (i.e., can and can't) tended to be produced correctly more often than DOES (as predicted by Santelmann et al. but not Van Valin) but was also produced correctly more often than WILL (as predicted by Van Valin but not by Santelmann et al.). Overall, WILL tended to be correct more often than DOES (as predicted by Santelmann et al.), but this difference reached significance only at $3 ; 5$.
Overall summary of proportional correct use. To summarize across all three developmental points and both constructions, the children were better at producing correct declaratives than correct questions with all auxiliaries except can at 3;2 (declaratives $M=66.4 \%$, questions $M=$ $61.7 \%$ ). Polarity effects decreased over development and were more substantial in questions than in declaratives, but when they emerged they consistently revealed better performance with positive than negative forms. At $2 ; 11$, there was a clear advantage for positive over negative forms in questions, which held across all three auxiliaries. However, this difference was observed only for does/3S forms in declaratives. By 3;2, only CAN showed an advantage for the positive over the negative form in questions. Polarity effects had disappeared completely from declaratives. By $3 ; 5$, there were no polarity effects for any auxiliary in either construction, despite the fact that performance was not at ceiling (overall $M \%$ correct $=53.68$ ).

Performance within each construction was affected by auxiliary form. Overall, there was a tendency for children to perform best with CAN, then WILL, followed by DOES in both constructions. At 2;11, the children performed better with CAN than with DOES in declaratives but not questions. At 3;2, there were no differences between forms in declaratives, but in questions there was an advantage for the positive form of can over does. At 3;5, there was an advantage for CAN over WILL and DOES in declaratives and for CAN and WILL over DOES in questions.

\section{Errors}

To investigate the children's errors further, we categorized them as errors of omission, agreement, double marking, uninversion, or auxiliary substitution. With the exception of auxiliary substitution errors (14.85\% of target responses, discussed later in this section), the children made very few errors in declaratives: Less than $1 \%$ of target responses were omission errors (total number $=$ 10 ), and less than $0.08 \%$ were double marking errors ( 1 error). Just over $2 \%$ ( 25 errors) were agreement errors with DOES where 3S marking was omitted from the auxiliary or main verb (e.g., "The penguin do tickle the baby," "My pig bounce the ball"). These are not analyzed further because CAN and WILL are not marked for number or person, making comparisons between auxiliaries difficult (the few agreement errors that did occur with these forms consisted of the use of a $3 \mathrm{~S}$ verb form with a modal, e.g., "He can reads the book").

In regard to questions, the children made a number of errors (Figures 1-3 show the proportions of each error type at $2 ; 11,3 ; 2$, and $3 ; 5$, respectively). Errors of omission comprised on average only $1.54 \%$ of target responses (seven errors in total) and agreement errors $0.64 \%$ (four 
Figure 1. The proportion of omission (om), uninversion (unin), double marking (dm), agreement (ag), and substitution (substit) errors for CAN, WILL, and DOES in questions at 2;11 (and standard errors).

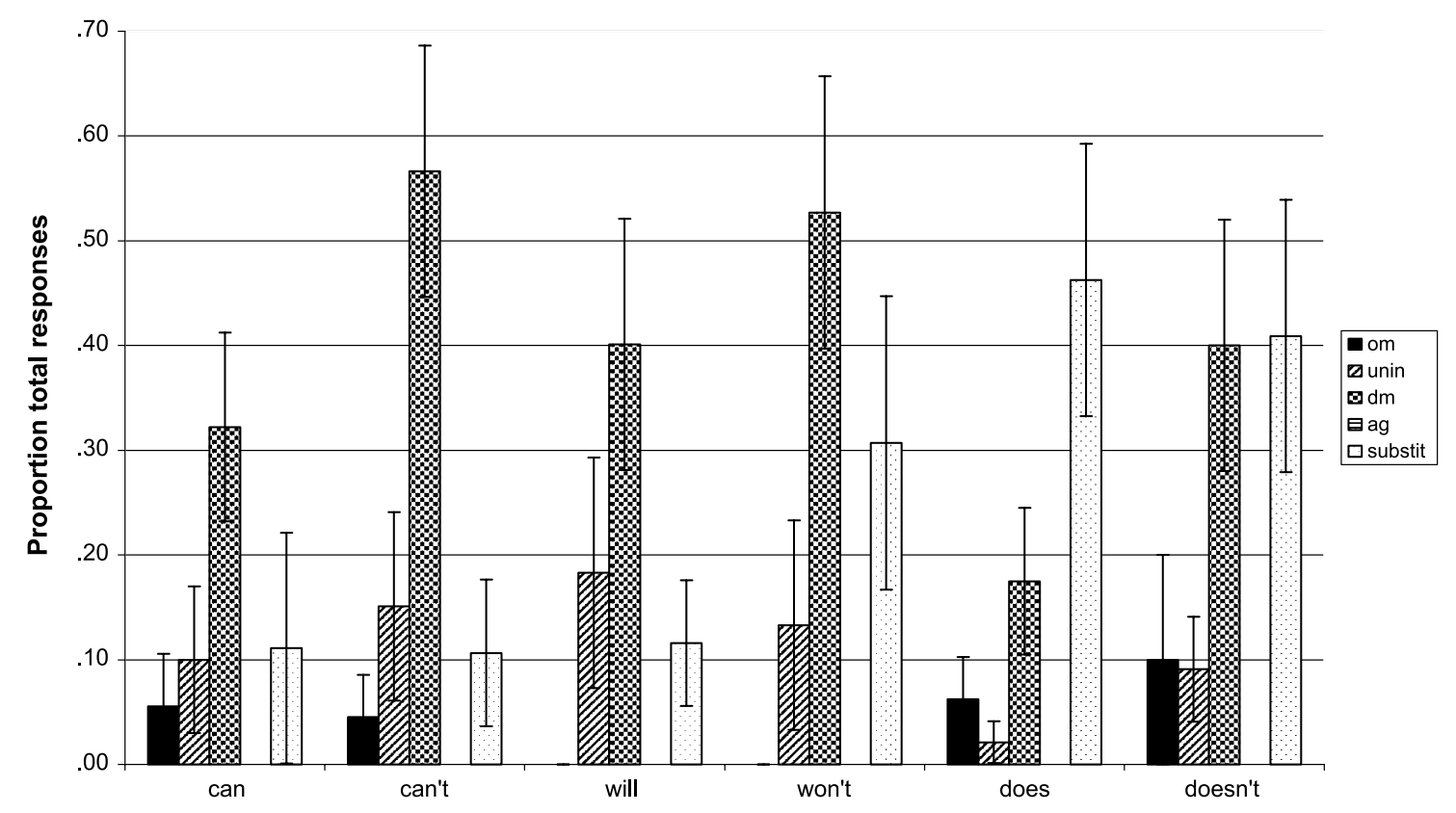

errors), so these are not analyzed further. The most common errors were double marking $(30.13 \%)$, uninversion $(4.51 \%)$, and auxiliary substitution errors $(41.67 \%)$. We investigated the patterning of these error types as a function of polarity and auxiliary.
Double marking errors in questions. Double marking errors (e.g., "Can Piglet can push the pram?") were the most frequent type of error but decreased in number throughout development, accounting for, on average, $41 \%$ of target utterances at $2 ; 11,29 \%$ at $3 ; 2$, and $21 \%$ at

Figure 2. The proportion of omission, uninversion, double marking, agreement, and substitution errors for CAN, WILL, and DOES in questions at 3;2 (and standard errors).

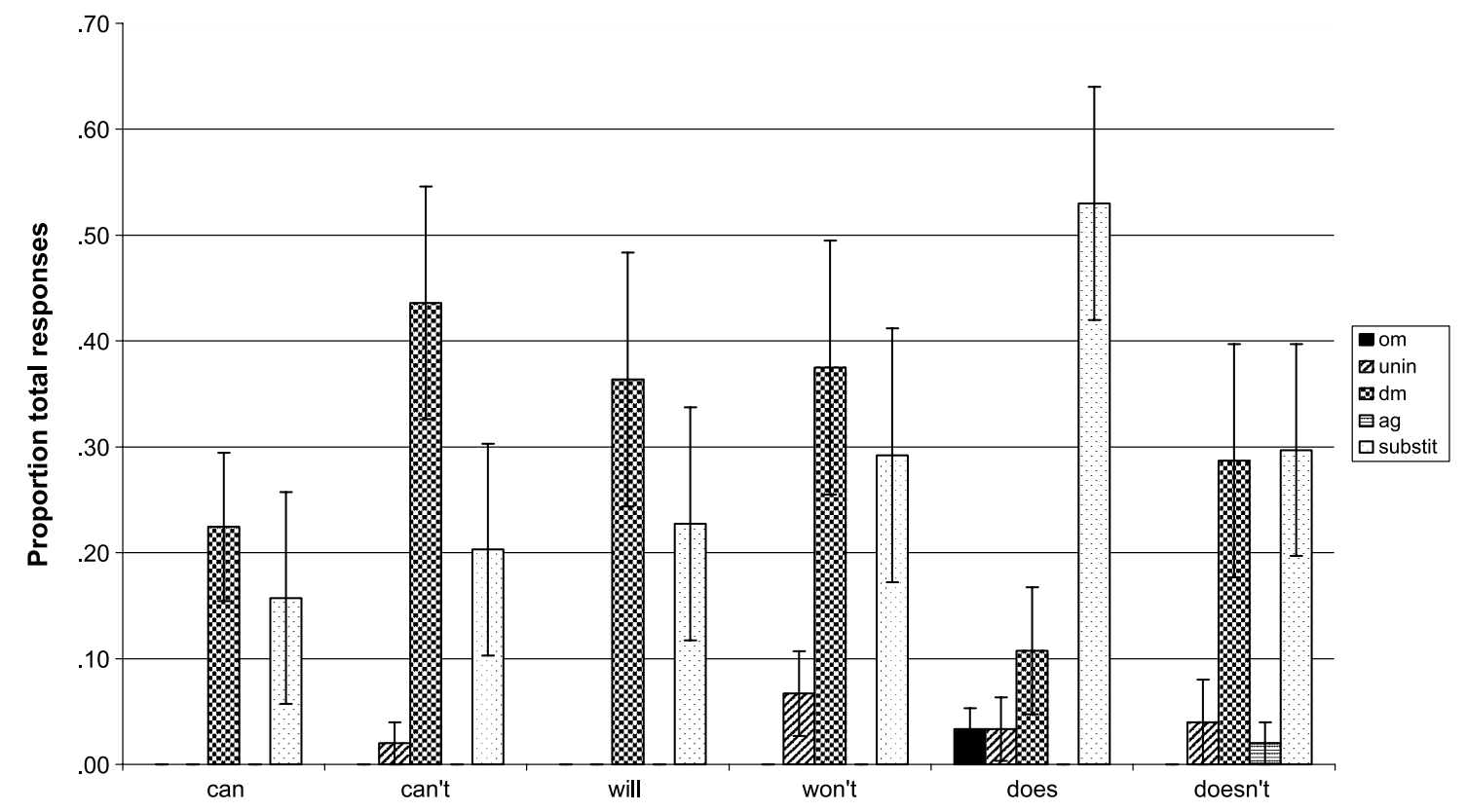


Figure 3. The proportion of omission, uninversion, double marking, agreement, and substitution errors for CAN, WILL, and DOES in questions at 3;5 (and standard errors).

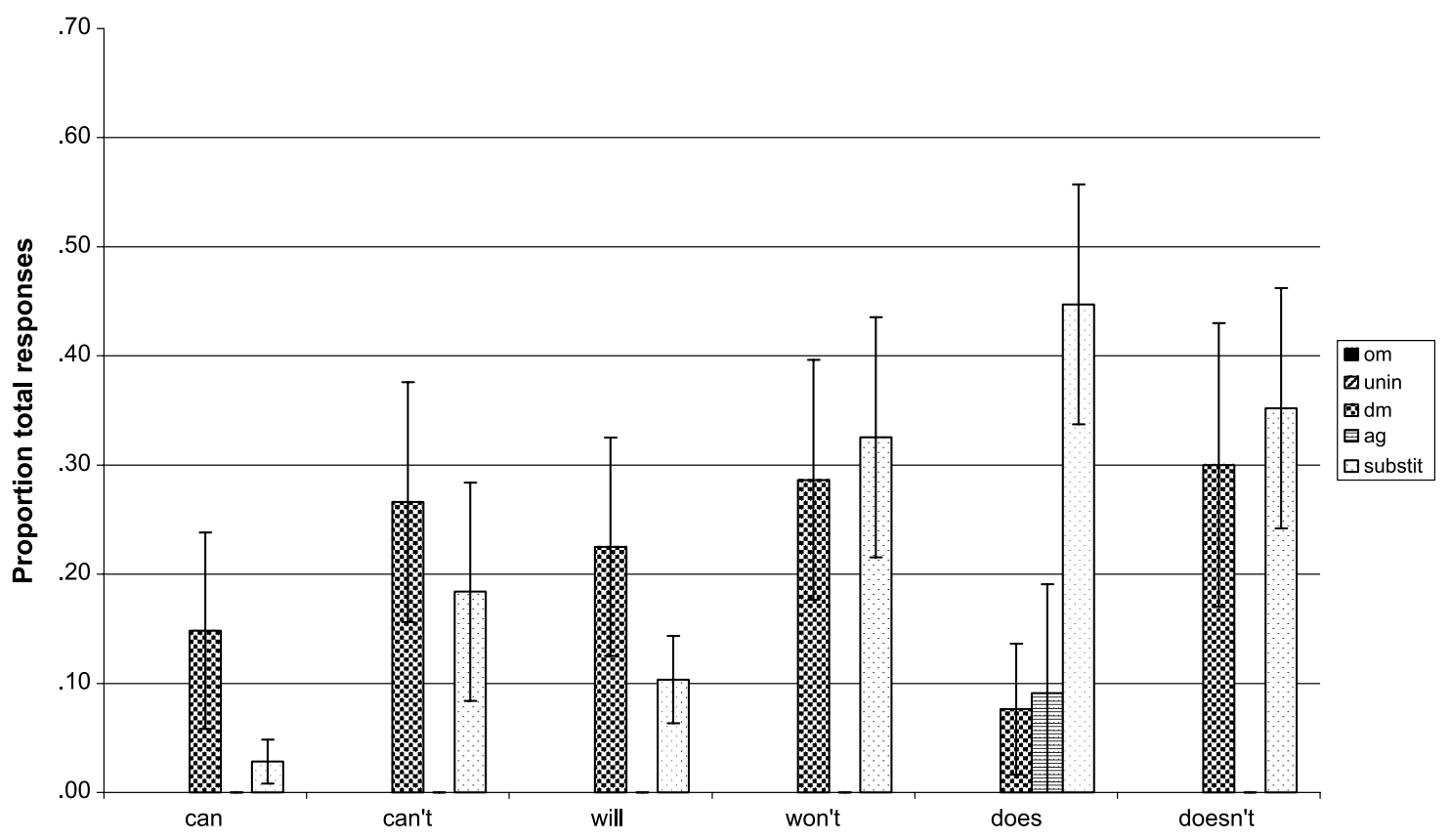

$3 ; 5$. The number of double marking errors produced for each target auxiliary and the auxiliaries that were used in utterance-initial position are shown in Table 2. Because the absolute number of double marking errors produced by individual children was fairly low, we pooled the errors across the children at each age.

Double marking errors can largely be accounted for by one of two strategies: either (a) the children produced the positive form of the target auxiliary in utteranceinitial position (and the target auxiliary in utteranceinternal position; e.g., "Can Piglet can't push the pram?") or (b) they produced is as a generic question marker in utterance-initial position with the target auxiliary in utterance-internal position (e.g., "Is Piglet can push the pram?"). Double marking errors were prevalent with positive as well as negative utterance-internal auxiliaries, although not as frequent (132 in negative questions as opposed to 82 in positive questions).

Age 2;11. At 2;11, the children produced most double marking errors with CAN (45.67\%) and WILL (46.33\%) and fewer with DOES (30\%), but this difference did not reach significance, $F(2,14)=1.28, p>.05, \eta^{2}=.15$. There was, however, a main effect of polarity, $F(1,7)=8.06$, $p=.025, \eta^{2}=.54$, but no interaction between the variables, $F(2,14)=0.19, p>.05, \eta^{2}=.03$. Children produced more double marking errors in negative questions (can't $=56.6 \%$, won't $=52.7 \%$, doesn't $=40.0 \%$ ) than in positive questions ( $\mathrm{can}=32.2 \%$, will $=40.1 \%$, does $=$ $17.5 \%)$ across auxiliaries as predicted by Guasti et al. (1995) and Van Valin (2002). Consistent with the claims of Guasti et al., all double marking errors in negative questions bar one ("Won't X won't") occurred with a positive auxiliary form in inverted position and the target negative form in utterance-internal position (e.g., "Can X can't," "Is X doesn't"). The children did, however, also produce a substantial number of double marking errors in positive questions, contrary to Guasti et al.'s prediction.

Ages 3;2 and 3;5. Again, the children produced more errors with CAN and WILL than with DOES (especially at $3 ; 2$ ), but this difference did not reach significance. There was again a tendency to produce more errors in negative questions than in positive questions (as predicted by Van Valin, 2002, and Guasti et al., 1995), but this difference did not reach significance. There was no interaction between the variables (all $p \mathrm{~s}>.05$ ).

Uninversion errors in questions. Uninversion errors were errors in which the children produced a sentence with declarative word order but question intonation (e.g., "Piglet can ride the bike?"). Although these are grammatically correct in some contexts within the children's dialect (to request clarification or express surprise), they are not correct within the context of this game. Uninversion errors were less common than double marking errors. There were only 24 errors overall. At $2 ; 11$, the mean overall rate of uninversion errors was $11.75 \%$ (total number of errors $=15$ ), reducing to $2.6 \%$ at $3 ; 2$ (number of errors $=9$ ), and by $3 ; 5$ the children made no uninversion errors with any auxiliary. Wilcoxon rank sum tests at 2;11 and $3 ; 2$ showed that there were no significant differences between positive and negative forms of CAN, WILL, or 
Table 2. Total number of double marking (DM) errors in questions with CAN, WILL, and DOES (total number of children producing the error).

\begin{tabular}{|c|c|c|c|c|c|c|c|c|c|}
\hline \multirow[b]{2}{*}{ Age and target aux } & \multicolumn{8}{|c|}{ Utterance-initial aux } & \multirow[b]{2}{*}{ Total no. DM errors (no. children) } \\
\hline & Can & Will & Does/Do & Is & Could & Can't & Won't & Doesn't/Don't & \\
\hline \multicolumn{10}{|l|}{$2 ; 11^{a}$} \\
\hline Can & 5 & 0 & $1 / 0$ & 3 & 0 & 0 & 0 & $0 / 0$ & $9(6)$ \\
\hline Can't & 5 & 0 & $2 / 0$ & 7 & 1 & 0 & 0 & $0 / 0$ & $15(9)$ \\
\hline Will & 2 & 9 & $0 / 0$ & 0 & 0 & 0 & 0 & $0 / 0$ & $11(6)$ \\
\hline Won't & 3 & 12 & $0 / 0$ & 2 & 0 & 0 & 1 & $0 / 0$ & $18(7)$ \\
\hline Does & 1 & 0 & $4 / 0$ & 1 & 0 & 0 & 0 & $0 / 0$ & $6(4)$ \\
\hline Doesn't & 0 & 0 & $9 / 0$ & 5 & 0 & 0 & 0 & $1 / 0$ & $15(6)$ \\
\hline Total & 16 & 21 & 16 & 18 & 1 & 0 & 1 & 1 & 74 \\
\hline \multicolumn{10}{|l|}{$3 ; 2^{a}$} \\
\hline Can & 12 & 0 & $0 / 0$ & 1 & 0 & 0 & 0 & $0 / 0$ & $13(6)$ \\
\hline Can't & 9 & 0 & $0 / 0$ & 7 & 0 & 3 & 0 & $0 / 0$ & $19(8)$ \\
\hline Will & 0 & 14 & $0 / 0$ & 2 & 0 & 0 & 0 & $0 / 0$ & $16(7)$ \\
\hline Won't & 0 & 13 & $0 / 0$ & 2 & 0 & 0 & 4 & $0 / 0$ & $19(6)$ \\
\hline Does & 0 & 1 & $2 / 0$ & 4 & 0 & 0 & 0 & $0 / 0$ & $7(4)$ \\
\hline Doesn't & 0 & 1 & $9 / 0$ & 3 & 0 & 0 & 0 & $0 / 1$ & $14(6)$ \\
\hline Total & 21 & 29 & 11 & 19 & 0 & 3 & 4 & 1 & 88 \\
\hline \multicolumn{10}{|l|}{$3 ; 5^{a}$} \\
\hline Can & 4 & 0 & $0 / 0$ & 5 & 0 & 0 & 0 & $0 / 0$ & $9(3)$ \\
\hline Can't & 4 & 0 & $0 / 0$ & 6 & 0 & 0 & 0 & $0 / 0$ & $10(5)$ \\
\hline Will & 1 & 5 & $0 / 0$ & 5 & 0 & 0 & 0 & $0 / 0$ & $11(6)$ \\
\hline Won't & 0 & 7 & $0 / 1$ & 5 & 0 & 0 & 0 & $0 / 0$ & $13(6)$ \\
\hline Does & 0 & 1 & $0 / 0$ & 4 & 0 & 0 & 0 & $0 / 0$ & $5(2)$ \\
\hline Doesn't & 0 & 1 & $4 / 1$ & 3 & 0 & 0 & 0 & $0 / 0$ & $9(4)$ \\
\hline Total & 9 & 14 & 6 & 28 & 0 & 0 & 0 & 0 & 57 \\
\hline Overall total & 46 & 64 & 33 & 65 & 1 & 3 & 5 & 2 & 219 \\
\hline
\end{tabular}

Note. aux $=$ auxiliary.

${ }^{a} \mathrm{Age}$ is represented as years; months.

DOES in the proportion of uninversion errors the children produced, contrary to the predictions of Santelmann et al. (2002) and Van Valin (2002). Similarly, Friedman's tests at $2 ; 11$ and $3 ; 2$ showed that there were no significant differences in the rates of uninversion errors produced across auxiliaries, regardless of polarity, contrary to the predictions of Guasti et al. (1995) and Van Valin (all $p \mathrm{~s}>.05$ ). However, given the small number of errors produced, a failure to find an effect is unsurprising.

Auxiliary substitution errors. The mean percentage of auxiliary substitution errors is shown in Table 3. Auxiliary substitution errors are errors in which the children produced an alternative auxiliary in place of the target form (e.g., child's response "Can Piglet move the chair?", target "Will Piglet move the chair?"; this is a can for will substitution). Auxiliary substitutions also included cases in which the child produced the correct auxiliary but with the incorrect polarity (but excluding double marking errors in which one of the auxiliaries was the correct polarity). As one reviewer pointed out, in questions these polarity reversals could be considered pragmatically acceptable responses to a request, making their categorization as errors inappropriate (e.g., "Can Piglet move the goal?" might be a suitable response to the request to ask Dobbin if Piglet can't move the goal). In practice, however, excluding them made very little difference to the results. ${ }^{4}$

\footnotetext{
${ }^{4}$ There were 21 reversed polarity errors in questions: In 3 of these errors, the children substituted can't for can ( 1 at $2 ; 11,1$ at $3 ; 2$, and 1 at $3 ; 5$ ), 8 were can for can't substitutions ( 1 at $2 ; 11,1$ at $3 ; 2$, and 6 at 3;5), 2 were does for doesn't substitutions ( 1 at 3;2 and 1 at 3;5), and 8 were will for won't substitutions ( 1 at $2 ; 11,2$ at $3 ; 2$, and 5 at $3 ; 5$ ). Including them as correct responses instead of auxiliary substitution errors had only three effects on the data. First, in the correct use analyses the marginally significant main effect of auxiliary at 3;2 disappeared (although it is important to note that the significant interaction with polarity remained); second, the nonsignificant difference between the proportion of correct can and will responses at 3;5 reached significance $(p=.02)$. Third, in the auxiliary substitution analysis the near-significant difference between the number of errors with does and will at 3;2 no longer reached significance, although the trend remained in the same direction.
} 
Table 3. Mean percentage auxiliary substitution errors as a function of target responses, and total number of substitution errors.

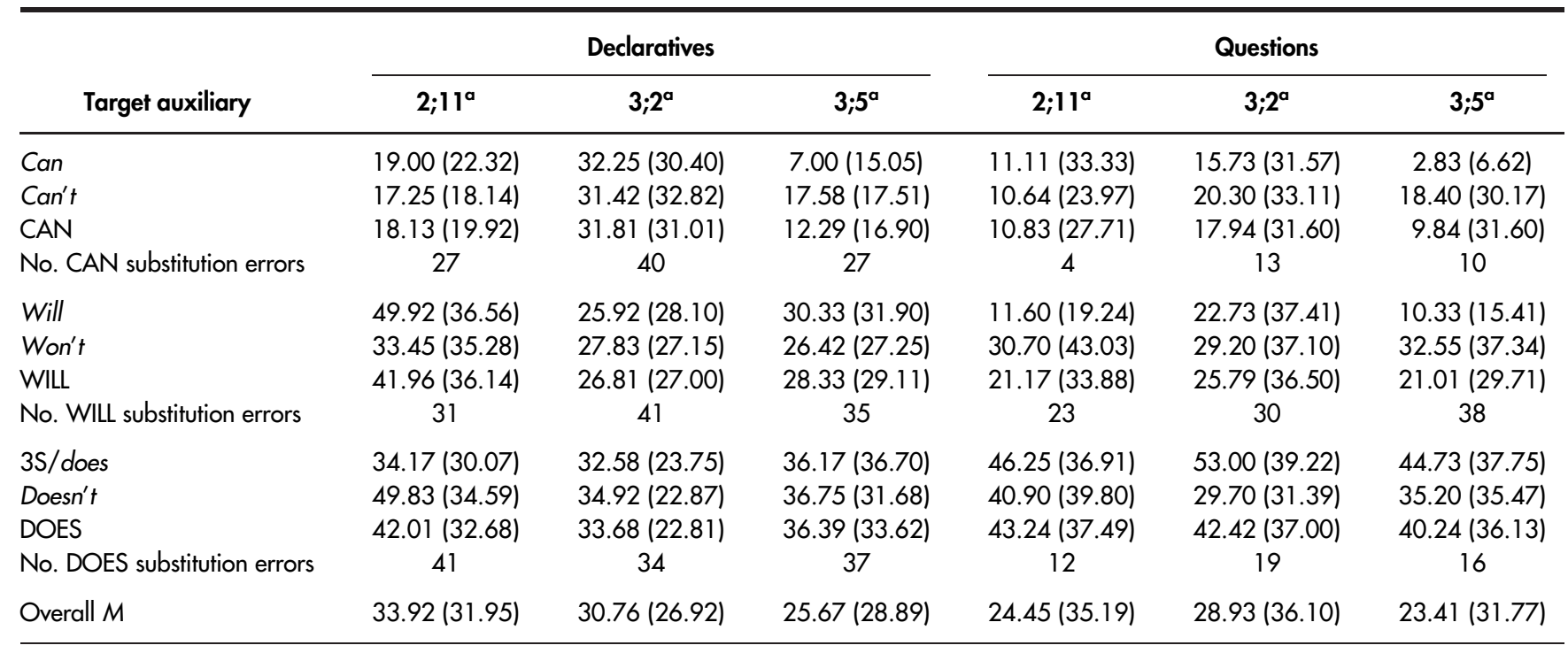

Note. Numbers in parentheses are standard deviations.

${ }^{a} \mathrm{Age}$ is represented as years;months.

Age 2;11. In declaratives, there was no effect of auxiliary, $F(2,20)=2.22, p>.05, \eta^{2}=.18$, or polarity, $F(1,10)=$ $0.002, p>.05, \eta^{2}=.00$, but there was a significant interaction between the variables, $F(2,20)=3.50, p=$ $.05, \eta^{2}=.26$. Pairwise comparisons revealed a marginally significant effect of polarity for DOES such that the children made more substitution errors for the negative form doesn't than for the positive form does $(p=.07)$. In questions, there was a main effect of auxiliary, $F(2,14)=8.02, p=.005, \eta^{2}=.53$, but no effect of polarity, $F(1,7)=1.04, p>.05, \eta^{2}=.13$, and no interaction between the variables, $F(2,14)=1.07, p>.05$, $\eta^{2}=.13$. Pairwise comparisons revealed that the children were significantly more likely to make auxiliary substitutions when the target form was DOES than when the target form was CAN $(p=.023)$ or WILL $(p=.013)$.

Age 3;2. In declaratives, there was no effect of auxiliary or polarity, and no interaction between the variables. Children made similar proportions of auxiliary substitution errors, irrespective of the target form. In questions, there was a main effect of auxiliary, $F(2,18)=4.85$, $p=.021, \eta^{2}=.35$, and a significant interaction between the variables, $F(2,18)=4.03, p=.036, \eta^{2}=.31$, although no main effect of polarity, $F(1,9)=.012, p>.05, \eta^{2}=.00$. Post hoc comparisons revealed a tendency for the children to make more substitution errors for does than for will ( $p=.053)$ and can $(p=.087)$, but there were no differences between the negative forms.

Age 3;5. At 3;5, in declaratives there was a main effect of auxiliary, $F(2,22)=4.19, p=.025, \eta^{2}=.29$; no effect of polarity, $F(1,11)=0.57, p>.05, \eta^{2}=.05$; and no interaction between the variables, $F(2,22)=1.33, p>.05$, $\eta^{2}=.11$. Pairwise comparisons revealed that the children were more likely to make auxiliary substitutions when the target form was DOES than when the target form was CAN ( $p=.034)$. In questions, there was a main effect of auxiliary, $F(2,16)=5.16, p=.019, \eta^{2}=.39$; no effect of polarity, $F(1,8)=0.83, p>.05, \eta^{2}=.09$; and no interaction between the variables, $F(2,16)=1.03, p>.05$, $\eta^{2}=.11$. Like declaratives, pairwise comparisons revealed that there was a tendency for the children to make more auxiliary substitutions when the target was DOES than when the target was CAN ( $p=.061$ ).

Analysis by form substituted for the target. The proportion of substitution errors accounted for by each auxiliary at each age in declaratives and questions is presented in Table 4. For the purposes of this analysis, we grouped together positive and negative forms of each auxiliary because there were few differences between forms in the pattern of substitution errors observed. There were very clear differences between declaratives and questions. In declaratives, CAN, WILL, and DOES each accounted for a large proportion of the auxiliary substitution errors from $2 ; 11$. In questions, CAN and IS account for the largest proportion of substitution errors from $2 ; 11$, with WILL accounting for a larger proportion from $3 ; 2$. In contrast to declaratives, the form DOES was hardly ever used in questions to substitute other auxiliaries, whereas the form IS appeared in questions but hardly ever in declaratives.

Role of input frequency. To investigate whether the patterns of auxiliary substitution and correct auxiliary use in questions might be determined by input frequencies of 
Table 4. Percentage substitution errors for CAN, WILL, and DOES accounted for by different auxiliaries.

\begin{tabular}{ccccccc}
\hline & \multicolumn{6}{c}{ Auxiliary form substituted for target } \\
\cline { 2 - 7 } Task type & CAN & WILL & DO $^{\mathrm{a}}$ & IS & COULD & WOULD \\
\hline Declaratives (N) & & & & & & \\
$2 ; 11^{\mathrm{b}}(100)$ & 34 & 35 & 23 & 7 & 1 & 0 \\
$3 ; 2^{\mathrm{b}}(115)$ & 38 & 37 & 22 & 0 & 0 & 3 \\
$3 ; 5^{\mathrm{b}}(97)$ & 19 & 36 & 23 & 1 & 1 & 21 \\
$M$ & 30.3 & 36.0 & 22.7 & 2.7 & 0.7 & 8.0 \\
Questions (N) & & & & & & \\
$2 ; 11^{\mathrm{b}}(39)$ & 36 & 10 & 0 & 41 & 13 & 0 \\
$3 ; 2^{\mathrm{b}}(59)$ & 17 & 22 & 7 & 54 & 0 & 0 \\
$3 ; 5^{\mathrm{b}}(64)$ & 44 & 36 & 5 & 16 & 0 & 0 \\
$M$ & 32.3 & 22.7 & 4.0 & 37.0 & 4.3 & 0 \\
\hline
\end{tabular}

Note. Substitution errors are combined across all three target auxiliaries.

aChildren substituted both do and does for the target auxiliaries; however, use of do was largely restricted to declaratives at 2;11 $(N=11)$, with only one example found in declaratives at $3 ; 2$ and in questions at $3 ; 5$. ${ }^{\mathrm{b}} \mathrm{Age}$ is represented as years;months.

specific auxiliaries (as predicted by the usage-based account), we calculated the frequency of CAN, DOES, and WILL in naturalistic data samples from the children's mothers recorded in their homes over the period from $2 ; 10$ to $3 ; 6$ (comprising approximately $25 \mathrm{hr}$ of recordings per mother-child dyad). We used the Computerized Language Analysis (CLAN) programs (MacWhinney, 2000) to count the overall frequency of the auxiliaries. The total number of auxiliaries produced by the mothers in declaratives and yes/no questions is presented in Table 5 .

The mothers produced substantially more declaratives and questions with CAN than with WILL or DOES; thus, the children's better performance with CAN than with DOES and WILL is consistent with the idea that

Table 5. Input frequencies of declaratives and yes/no questions with CAN, WILL, and DOES.

\begin{tabular}{lccr}
\hline Auxiliary & Declaratives & Yes/no questions & \multicolumn{1}{c}{ Total } \\
\hline Can & 6,191 & 3,944 & 10,135 \\
Can't & 1,866 & 113 & 1,979 \\
CAN & 8,057 & 4,057 & 12,114 \\
Will & 1,295 & 401 & 1,696 \\
Won't & 642 & 33 & 675 \\
WILL & 1,937 & 434 & 2,371 \\
Does & 549 & 1,029 & 1,578 \\
Doesn't & 943 & 111 & 1,054 \\
DOES & 1,492 & 1,140 & 2,632 \\
Total & 11,486 & 5,631 & 17,117 \\
\hline
\end{tabular}

they learn how to produce correct questions with highfrequency auxiliaries earlier than those that occur with low frequency in the input. Similarly, the children's better performance with positive than negative auxiliaries in questions might be attributed to the fact that positive auxiliary forms tended to be more frequent in the input than negative forms. However, there were also effects not explained by input frequency. In declaratives, the children performed equally well with negative as with positive forms, despite the fact that negative forms were substantially less frequent in their input. The exception was DOES; the mothers produced more examples of doesn't than does, but despite this, the children had a tendency to perform better with does than doesn't (which reached significance at 2;11). The tendency for children to produce more correct questions with WILL than with DOES (significant at 3;5) is not compatible with the input data because the mothers produced substantially more correct questions with DOES than with WILL.

To test whether children rely on well-known, highly frequent utterance-initial auxiliaries when they make errors in questions, we compared our data with the most frequent aux + subj combinations found in yes/no questions in speech addressed to 2-year-olds. Cameron-Faulkner, Lieven, and Tomasello (2003, based on data from the Manchester corpus [Theakston, Lieven, Pine, \& Rowland, 2001]) reported that the most frequent frames in the input were Are you/they/we (20\%), Can you/I (11\%), Do you (14\%), Is it/that/helthis/she (15\%), and Shall we/I/Mummy (15\%). These frames were also highly frequent in the speech from our 12 children's mothers (accounting for 9\%, 14\%, $19 \%, 5 \%$, and $11 \%$ of yes/no questions with auxiliaries, respectively). The frame Does it accounted for just $1 \%$ of yes/no questions in both Cameron-Faulkner et al.'s data and the input data of the children studied in the present research, although no frames based around WILL were reported by Cameron-Faulkner et al. (in the input of the children reported here, the most frequent will question frame was will you, accounting for $0.87 \%$ of yes/no questions). In relation to the current findings, we make three observations. First, the high frequency of $d o$ in yes/no questions does not appear to be reflected in high levels of accurate use of the 3S form does. Second, the high frequency of frames based around positive forms may explain why the vast majority of double marked questions contain a positive auxiliary form in utterance-initial position. Third, the large number of $i s$ questions in the input may explain why this form is often substituted for CAN, WILL, and DO and produced in double marked questions with the target in utterance-internal position, even when the target itself is of high frequency, as in the case of can. Although questions with are are also frequent, the elicitation contexts used in this study were $3 \mathrm{~S}$ contexts, so we would not expect to find children using this form as a default option in the games. 


\section{$\overline{\text { Discussion }}$}

The aim of this research was to determine the pattern of auxiliary acquisition between $2 ; 10$ and $3 ; 6$ by testing 12 children in an elicitation paradigm at six time points over the course of development. We elicited positive and negative forms of auxiliary DOES and the modals CAN and WILL in declaratives and yes/no questions.

The first aim of this study was to investigate whether there was any evidence that children recognize individual auxiliaries as examples of the abstract category AUX, as evidenced by similar patterns of use of an auxiliary across constructions (Aim 1a) and similar patterns of use across auxiliaries within a construction (Aim 1b). There was little evidence for similar patterns of use across constructions: At all ages, performance in declaratives was significantly better than in questions, and this was the case for all but one of the auxiliaries tested (the exception was can at 3;2). There was also little evidence of generalization across CAN, WILL, and DOES within constructions. In both declaratives and questions, CAN tended to be produced correctly most often, followed by WILL and then DOES, although differences did not always reach significance, with the strongest and most significant effects occurring between CAN and DOES.

Aim 2 was to investigate whether children understand the relation between positive and negative forms of CAN, WILL, and DOES in both declaratives and questions to an extent that would allow them to generalize knowledge of how to use the forms, resulting in similar patterns of use. In declaratives, it seems that children did relate positive and negative forms of these auxiliaries. With the exception of DOES at $2 ; 11$, there were no effects of polarity on the children's performance with declaratives. In this task, a correct response required the children to produce a form of opposite polarity to that modeled by the experimenter; thus, correct use implies knowledge of the relation between forms. The fact that the children were so successful shows not only that they could generalize correct use from positive to negative (and/or vice versa) but also that they had already established the semantic link between positive forms and the equivalent negatives.

The pattern of results observed in questions is somewhat different, however. At $2 ; 11$, the children performed better with positive than negative questions across the board, reflecting very low levels of correct use in negative questions. By 3;2, an effect of polarity was observed only for CAN, and by $3 ; 5$, although negative auxiliaries were produced correctly less often than positive auxiliaries, this difference did not reach significance. Data from the uninversion errors revealed no significant differences at any age. Double marking errors were more prevalent in negative than positive forms at $2 ; 11$ across the board, but there were no significant differences at $3 ; 2$ and $3 ; 5$. Taken together, the results from declaratives and questions suggest that the children recognized the relation between positive and negative forms but that this alone was not sufficient to ensure correct use of negative forms in questions, at least at the earlier stages. ${ }^{5}$ These data suggest that negation in questions causes problems for children in the earliest stages of auxiliary acquisition.

The third aim of this study was to investigate some predictions from current theories. Santelmann et al. (2002) predicted that levels of performance in both constructions should be similar for the modals because the only difference between declaratives and questions is the positioning of the auxiliary, which is governed by principles of UG. We would also expect to see similar levels of use of CAN and WILL in questions because neither is marked for tense, agreement, or person; both are reasonably frequent in the input to children; and both exhibit the same syntactic behavior. However, children are predicted to make errors with DO in questions because additional knowledge regarding how to mark tense, person, and number is required to allow correct use of DO in questions (see also Stromswold, 1990). As predicted, there was a strong tendency for CAN to outperform DOES in questions and a slight tendency for WILL to occur correctly more often than DOES, although this difference reached significance only at $3 ; 5$. However, the children also typically performed better with CAN than WILL in questions (although the difference was significant only in the overall analysis), which is not predicted by Santelmann et al.'s (2002) theory. In addition, contrary to the prediction, the same differences between auxiliaries were found in declaratives, albeit at lower rates of error. Also contrary to the prediction, the children performed more poorly on questions than declaratives with all auxiliary types, not just those with DOES. Thus, although children did appear to face problems producing questions with DOES, their problems were not confined to this form. This conclusion must be mediated by the fact that the questions task was clearly a harder task (indicated by the fact that the children

\footnotetext{
${ }^{5}$ A reviewer suggested that the children's problems with negative questions may stem from the nature of the task. In particular, this reviewer suggested that it might be difficult to provide the appropriate pragmatic context for the use for negative questions, which could have depressed children's performance. However, this is an unlikely explanation for the data for three reasons: (a) Children produced equal numbers of target responses for positive and negative questions at all ages, suggesting that they found the task of constructing the relevant question equally easy/difficult for both positive and negative forms; (b) the pattern of errors mirrors that found in the literature using naturalistic data, suggesting that it is not task specific (see Rowland \& Pine, 2000); and (c) it was in fact slightly easier to construct an appropriate pragmatic context for negative questions, because these required the child to question a third party's refusal/failure to perform a behavior, a relatively common occurrence in naturalistic situations.
} 
produced fewer target responses across the board in the questions task). In future studies, using comparable tasks (e.g., comparing the question task used here with a declaratives task in which the child had to respond to a question) would overcome this problem (see Dąbrowska, Rowland, \& Theakston, 2009). That said, these results are consistent with work on naturalistic data (Rowland, 2007 ) that suggests that producing questions with modal auxiliaries is not as straightforward as Santelmann et al. predicted.

In contrast, Van Valin (2002) predicted that children will show differential performance in questions depending on the transparency of the auxiliary as a marker of tense. Because DOES is more transparently marked for tense than the modals, and CAN is more transparently marked for tense than WILL, one might expect to see dissimilar patterns of use between these auxiliaries in questions. Similarly, negative auxiliaries will not initially be recognized as tensed and thus not placed utterance initially. Consistent with the prediction, the children typically performed better with CAN than WILL in questions (although the difference was significant only in the overall analysis) and tended to perform better with positive questions than negative questions, especially at the earliest age. According to Van Valin, the disparity between positive and negative forms at $2 ; 11$ is likely to reflect high levels of uninversion or double marking errors for negative forms. As predicted, double marking errors, in particular, occurred with high frequency in negated questions.

However, Van Valin's (2002) prediction that in questions (but not in declaratives) DOES should be less susceptible to errors than the modals was not upheld by our data. In fact, CAN occurred correctly substantially more often than DOES, and WILL tended to occur correctly more often than DOES. In addition, contrary to the prediction, the children's performance in declaratives mirrored the pattern of performance in questions, albeit at lower rates of error. Focusing on errors that seem to result from problems with auxiliary placement in questions (double marking and uninversion errors) also failed to provide unequivocal support for the theory. Uninversion errors were equally prevalent with all three auxiliary types, although this is perhaps unsurprising given that they were rare. However, there were no significant auxiliary effects in double marking errors, which were much more frequent, either. There was a tendency for CAN and WILL to attract more double marking errors than DOES (consistent with Van Valin's theory), but these differences were not significant at any age.

Guasti et al.'s (1995) theory predicts that children will make the (incorrect) assumption that negation should be marked clause internally rather than through inversion of the negated element. This predicts high levels of error in questions with negative auxiliaries but not in questions with positive auxiliaries and not in declaratives. As predicted, there were more striking effects of negation in questions than in declaratives; error rates were higher in negative than in positive questions at the earliest age $(2 ; 11)$, and some effects remained even at $3 ; 2$. As predicted, the disparity between positive and negative forms at $2 ; 11$ reflected high levels of uninversion or double marking errors for negative forms. Double marking errors, in particular, occurred with high frequency in negated questions.

However, a closer look at the data suggests that there may be some inconsistencies between our data and Guasti et al.'s (1995) predictions. In particular, correct use and double marking errors coexisted for a relatively long period of time (6 months, from $2 ; 11$ to $3 ; 5) .{ }^{6}$ According to the theory, there is no obvious reason why double marking errors with an auxiliary should persist once children are correctly placing the negated form of that auxiliary in utterance-initial position because this would presumably signal that the child had recognized the correct rule. More important is the fact that double marking errors occurred in positive question forms (albeit at lower rates of error), with no significant differences observed between positive and negative forms in the proportion of double marking errors at 3;2 and 3;5, thus suggesting that negation in itself cannot provide a full explanation for the presence of double marking errors.

Finally, we set out to investigate whether some of the core factors underlying constructivist approaches to language acquisition might shed some light on our data, in particular by investigating patterns of responses when the children attempted to produce CAN, WILL, and DOES in questions. A number of previous studies have highlighted a role for lexically based frames organized around specific $w h$-words, auxiliaries, and subjects (usually pronominal forms) in predicting children's use of correct questions (Dąbrowska, 2000; Dąbrowska \& Lieven, 2005; Rowland, 2007; Rowland \& Pine, 2000), a close relation between the frames children learn early in acquisition and the frequency of these combinations in the input (e.g., Rowland \& Pine, 2000; Rowland, Pine, Lieven, \& Theakston, 2005; Theakston et al., 2001, 2005; Theakston, Lieven, Pine, \& Rowland, 2002, 2004), and a tendency for children to substitute lower frequency forms with higher frequency forms (Akhtar, 1999; Kidd et al., 2006; Matthews et al., 2005).

Our first prediction was that children's errors will pattern differently according to construction (declarative/ question) and auxiliary identity (can, can't, will, won't, does, doesn't). This prediction was upheld to an extent, in

\footnotetext{
${ }^{6}$ Although we counted utterances with an inverted positive auxiliary and clause-internal not as correct instances of negative questions (whereas Guasti et al. coded these as incorrect questions), in fact these kinds of utterances accounted for just $20 \%, 13 \%$, and $7 \%$ of correct questions at $2 ; 11$, $3 ; 2$, and $3 ; 5$, respectively.
} 
that our results revealed a complex interaction among construction, polarity, and auxiliary, but there was more generalization across constructions and auxiliaries than one might expect from children working with purely lexically based schemas. For example, our results suggest that the children recognized the relation between positive and negative forms, although this alone was not sufficient to ensure correct use of negative forms in questions, at least at the earlier stages. Similarly, although CAN tended to be produced correctly most often, followed by WILL and then DOES, these differences did not always reach significance, with the strongest and most significant effects occurring between CAN and DOES.

Second, we tested whether children learn highfrequency auxiliaries in specific constructions earlier than those that occur with lower frequency in the input. Consistent with the prediction, we found that yes/no questions starting with can are more frequent than questions beginning with will and does in the input, which may go some way toward explaining the higher proportional correct use of CAN over DO, although not why performance with WILL was also higher than with DO at 3;5. We also found that the high frequency of $d o$ in yes/no questions does not appear to be reflected in high levels of accurate use of the $3 \mathrm{~S}$ form does, suggesting that exposure to questions with do does not allow the children to produce correct questions with does, which one might expect if the children were freely generalizing across auxiliary forms.

Third, we tested the idea that children rely on wellknown, high-frequency utterance-initial auxiliaries when they make double marking errors in questions and that children show a tendency to substitute high-frequency forms for lower frequency forms. A detailed analysis of the children's questions revealed that children tended to produce double marked questions with either the correct auxiliary in positive form in utterance-initial position (with either the positive or negative form in clauseinternal position) or with is in inverted position with the target auxiliary in clause-internal position. When children produced auxiliary substitutions, they predominantly produced questions with either can or is in inverted position. An examination of data from the Manchester corpus (reported in Cameron-Faulker et al., 2003) and from spontaneous speech data from the mothers of the children we studied in the present research revealed that these two auxiliaries are very frequent in yes/no questions and are the only high-frequency forms that are appropriate for use in $3 \mathrm{~S}$ contexts, with the exception of shall. This suggests that the children are relying on high-frequency forms in their production of questions. However, if this is the case, it is clear that children are not basing their responses on the specific high-frequency frames from the input (e.g., Can I/you) but instead are combining a high-frequency auxiliary with a novel subject. In this study, children's questions predominantly took the form auxiliary + Piglet/the Piglet (and, to a lesser extent, auxiliary + he), reflecting the particular contexts used in the study. Thus, we have to assume that the children's knowledge extends beyond the specific auxiliary + subject combination to include at least a variable subject.

However, interpretation of the pattern of auxiliary substitution errors must be made with care, because the mechanism behind the errors is unclear. ${ }^{7}$ Auxiliary substitution errors might arise for two reasons. First, children have not yet learned how to produce declaratives and/or questions correctly with some auxiliaries, and this lack of knowledge is syntactic rather than semantic. Children might therefore be expected to make substitution errors more often with forms with which they are less familiar, perhaps with different patterns of error between constructions (e.g., producing "Can Piglet" questions because they do not know how to construct "Will Piglet" questions). A second possibility is that children may be making substitutions because they do not yet understand the meaning of some auxiliaries and have not grasped the subtle distinctions between the contexts presented by the experimenter for use of each target form. Thus, lower performance with some auxiliaries (in this task and perhaps the avoidance/omission of questions with these auxiliaries in spontaneous data) might reflect a lack of semantic knowledge about the meaning of the auxiliary rather than a lack of syntactic knowledge.

The current work does not allow us to distinguish between these two explanations; however, the fact that the children substitute is for does and the modals in questions is pertinent, because all of these substitutions occur with unmarked verb forms resulting in ungrammatical questions, for example, "Is Piglet move the chair?" In addition, these questions sometimes contain a form of DO, a $3 \mathrm{~S}$ verb form, or a modal (e.g., "Is Piglet doesn't lift the basket," "Is the piggy drives the car?", "Is Piglet do open book?", "Is the piggy will bounce the sponge?"). In fact, a substantial proportion of the substitution errors $(49 \%, 36 \%$, and $17 \%$ at $2 ; 11,3 ; 2$, and $3 ; 5$, respectively) were double marked, that is, they contained both an utterance-initial and internal auxiliary (neither

\footnotetext{
${ }^{7}$ It is important to note that the pattern of results for auxiliary substitution errors does not directly mirror the pattern of results observed for correct use. This means that auxiliary substitution errors are not the only reason we observed differences in the levels of correct use between the auxiliaries. For example, the auxiliary substitution data cannot explain the children's more accurate production of declaratives with CAN over DOES at $2 ; 11$ or with CAN over WILL at 3;5. Similarly, in questions there is no effect of auxiliary on rates of correct use at $2 ; 11$, although we observed an effect of auxiliary at this age for substitution errors, and substitutions cannot explain the difference in proportional correct use in questions at 3;5 between WILL and DOES.
} 
of which was the target). Of these double marking errors, the majority occurred where the target was a negative form (68\%, $62 \%$, and $82 \%$ at $2 ; 11,3 ; 2$, and $3 ; 5$, respectively), and the majority were produced with utterance-initial can or is $(74 \%, 81 \%$, and $55 \%$ at $2 ; 11,3 ; 2$, and $3 ; 5$, respectively). This contrasts with the variation in the clause-internal auxiliary form produced, where forms of can and is combined account for just 58\% (82\% of these were can't), $10 \%$, and $0 \%$ of auxiliaries at $2 ; 11,3 ; 2$, and $3 ; 5$, respectively. These data suggest that when children produce auxiliary substitutions in questions they often produce a double marked question typically beginning with either can or is, but there is somewhat more variation in the auxiliaries found in utterance-internal position. Unfortunately, the number of double marked questions with an utterance-initial is may have been artificially boosted by the use of $i s$ questions in the training trials of the questions game. Future research should use different question types in the training trials. However, because this cannot be an explanation for the questions that start with can, we should also consider the possibility that the pattern of substitution errors may reflect the fact that children are producing questions based around lexical frames and resort to using familiar forms when unsure what to do.

\section{Overall Discussion: Comparison of Part 1 and Part 2}

In this final section we draw comparisons between the children's use of BE (detailed in Part 1; Theakston \& Rowland, this issue) and their use of CAN, WILL, and DOES. On the one hand, the children showed improvements with age in their production of declaratives with all auxiliary forms, although the precise developmental point at which significant improvements were observed differed (forms of BE showed significant improvement between $2 ; 11$ and 3;2, whereas CAN, WILL, and DOES showed much more gradual improvement between 2;11 and $3 ; 5)$. On the other hand, similar improvements were not seen in yes/no questions with $\mathrm{BE}$, although the children improved in their production of yes/no questions with CAN, WILL, and DOES between 2;11 and 3;2 and again between $3 ; 2$ and 3;5. Because the children's performance in yes/no questions with are remained at around $50 \%$, one cannot argue that the children were at ceiling with this form. Neither can one claim that agreement marking per se causes problems, because improvements are seen in the children's use of DOES. In general terms, the differential effects of age suggest that, at least to some extent, the different auxiliaries are following different paths of acquisition.

These data are problematic for both generativist and constructivist theories as they currently stand. This study provides not only some evidence that auxiliaries may develop in parallel (e.g., as evidenced by the lack of consistent significant differences between CAN and WILL; the similar performance in declaratives with is and are; and similar levels of performance with positive and negative forms of CAN, WILL, and DOES in declaratives) but also some evidence for differential paths of acquisition (e.g., is and are in questions, CAN vs. DOES in declaratives and questions, polarity effects in questions but not declaratives). Although current generativist approaches predict differential paths of acquisition according to whether auxiliaries show idiosyncratic behavior in inversion (Santelmann et al., 2002; Stromswold, 1990), or the polarity of the auxiliary (Guasti et al., 1995), our data do not completely accord with their predictions. It seems that the differences observed cannot be predicted on the whole by positing relatively abstract factors that are expected to affect children's correct use of individual auxiliaries, for example, DO-support and associated problems with inversion, the presence or absence of explicit tense marking, or the polarity of the auxiliary. In addition, the data fail to support the idea that children have an adult-like understanding of the relation between different forms marked for tense, number, and person, even at age $3 ; 5$.

On the other hand, although constructivist theories are better able to explain the differences in use between auxiliaries, they cannot account for early acquired similarities in patterns of use that suggest some degree of generalization across auxiliaries. Our data suggest that the children's knowledge goes beyond tightly defined lexically based formulae, although it is still only partial and subject to error. Although constructivist approaches assume that children develop more abstract representations over development, it is difficult to determine the age at which such representations are predicted to emerge. This means that almost any pattern of acquisition can be accounted for simply by claiming that children have reached some intermediate stage in development where some linguistic representations are more abstract and others are still heavily lexically based. Theoretical work is needed to pin down which constructions are predicted to become more abstract early and which resist abstraction, remaining lexically based until much later in development. An additional problem is that the theory as it currently stands does not allow us to differentiate auxiliaries that show similar patterns of use but yet have been acquired separately, and those for which similar patterns of use reflect an underlying abstraction. Although the development of abstraction is thought to depend on complex distributional patterns in the input, we currently know very little about exactly how such factors determine development. Detailed theoretical work and analysis are required to allow researchers to investigate the relation between the distributional nature of 
the input children receive and the pattern of acquisition observed, in particular for complex linguistic items such as auxiliaries.

\section{Acknowledgments}

This research was funded by Economic and Social Research Council Grant RES-000-23-0673. A great deal of thanks is due to Jess Butcher and Debbie Anderson, who carried out the extensive data collection for this study. We also thank the parents and children who gave up their time to take part in this research.

\section{References}

Akhtar, N. (1999). Acquiring basic word order: Evidence for data-driven learning of syntactic structure. Journal of Child Language, 26, 339-356.

Ambridge, B., \& Rowland, C. F. (2009). Predicting children's errors with negative questions: Testing a schemacombination account. Cognitive Linguistics, 20, 225-226.

Ambridge, B., Rowland, C. F., Theakston, A., \& Tomasello, M. (2006). Comparing different accounts of non-inversion errors in children's non-subject wh-questions: "What experimental data can tell us?" Journal of Child Language, 30, 519-557.

Cameron-Faulkner, T., Lieven, E. V. M., \& Tomasello, M. (2003). A construction based analysis of child directed speech. Cognitive Science, 27, 843-873.

Croft, W. (2001). Radical construction grammar: Syntactic theory in typological perspective. Oxford, UK: Oxford University Press.

Dąbrowska, E. (2000). From formula to schema: The acquisition of English questions. Cognitive Linguistics, 11, 83-102.

Dąbrowska, E., \& Lieven, E. V. M. (2005). Developing question constructions: Lexical specificity and usage-based operations. Cognitive Linguistics, 11, 437-474.

Dąbrowska, E., Rowland, C. F., \& Theakston, A. L. (2009). The acquisition of questions with long-distance dependencies. Cognitive Linguistics, 20, 571-597.

Fenson, L., Dale, P., Reznick, S., Thal, D., Bates, E., Hartung, J., et al. (1993). The MacArthur Communicative Development Inventories: User's guide and technical manual. San Diego, CA: Singular.

Fletcher, P. (1985). A child's learning of English. Oxford, United Kingdom: Blackwell.

Goldberg, A. (1995). Constructions: A construction grammar approach to argument structure. Chicago: University of Chicago Press.

Goldberg, A. (2006). Constructions at work: The nature of generalization in language. Oxford, UK: Oxford University Press.

Guasti, M., Thornton, R., \& Wexler, K. (1995). Negation in children's questions: The case of English. In D. MacLaughlin $\&$ S. McEwen (Eds.), Proceedings of the 19th Annual Boston University Conference on Language Development (pp. 228-239). Somerville, MA: Cascadilla Press.
Hurford, J. (1975). A child and the English question formation rule. Journal of Child Language, 2, 299-301.

Kidd, E., Lieven, E. V. M., \& Tomasello, M. (2006). Examining the role of lexical frequency in children's acquisition and processing of sentential complements. Cognitive Development, 21, 93-107.

Langacker, R. W. (1991). Foundations of cognitive grammar: Vol. 2. Descriptive application. Stanford, CA: Stanford University Press.

MacWhinney, B. (2000). The CHILDES project: Tools for analyzing talk. Vol. 1: Transcription format and programs (3rd ed.). Mahwah, NJ: Erlbaum.

Maratsos, M., \& Kuczaj, S. (1978). Against the transformationalist account: A simpler analysis of auxiliary overmarkings. Journal of Child Language, 5, 337-345.

Matthews, D., Lieven, E. V. M., Theakston, A. L., \& Tomasello, M. (2005). The role of frequency in the acquisition of English word order. Cognitive Development, 20, 121-136.

Richards, B. (1990). Language development and individual differences: A study of auxiliary verb learning. Cambridge, UK: Cambridge University Press.

Rowland, C. F. (2007). Explaining errors in children's questions. Cognition, 104, 106-134.

Rowland, C. F., \& Fletcher, S. (2005). The effect of sampling on estimates of lexical specificity and error rates. Journal of Child Language, 33, 859-878.

Rowland, C. F., \& Pine, J. M. (2000). Subject-auxiliary inversion errors and wh-question acquisition: "What children do know?" Journal of Child Language, 27, 157-181.

Rowland, C. F., Pine, J. M., Lieven, E. V. M., \& Theakston, A. (2005). The incidence of error in young English children's wh-questions. Journal of Speech, Language, and Hearing Research, 48, 384-405.

Santelmann, L., Berk, S., Austin, J., Somashekar, S., \& Lust, B. (2002). Continuity and development in the acquisition of inversion in yes/no questions. Dissociating movement and inflection. Journal of Child Language, 29, 813-842.

Stromswold, K. J. (1990). Learnability and the acquisition of auxiliaries. Unpublished doctoral dissertation, Massachusetts Institute of Technology.

Theakston, A. L., Lieven, E. V. M., Pine, J. M., \& Rowland, C. F. (2001). The role of performance limitations in the acquisition of verb-argument structure. Journal of Child Language, 28, 127-152.

Theakston, A. L., Lieven, E. V. M., Pine, J. M., \& Rowland, C. F. (2002). Going, going, gone: The acquisition of the verb "go." Journal of Child Language, 29, 783-811.

Theakston, A. L., Lieven, E. V. M., Pine, J. M., \& Rowland, C. F. (2004). Semantic generality, input frequency and the acquisition of syntax. Journal of Child Language, 31, 61-99.

Theakston, A. L., Lieven, E. V. M., Pine, J. M., \& Rowland, C. F. (2005). The acquisition of auxiliary syntax: BE and HAVE. Cognitive Linguistics, 16, 247-277.

Tomasello, M. (2000). Do young children have adult syntactic competence? Cognition, 74, 209-253.

Tomasello, M. (2003). Constructing a language: A usagebased theory of language acquisition. Cambridge, MA: Harvard University Press. 
Tomasello, M., \& Stahl, D. (2004). Sampling children's spontaneous speech: How much is enough? Journal of Child Language, 31, 101-121.

Van Valin, R. (2002). The development of subject-auxiliary inversion in English questions: An alternative analysis. Journal of Child Language, 29, 161-175.

Wiig, E., Secord, W., \& Semel, E. (2000). Clinical Evaluation of Language Fundamentals Preschool UK. London: Psychological Corporation.
Received February 13, 2008

Revision received October 3, 2008

Accepted April 1, 2009

DOI: 10.1044/1092-4388(2009/08-0037a)

Contact author: Caroline F. Rowland, University of Liverpool, School of Psychology, Liverpool L69 7ZA, United Kingdom. E-mail: crowland@liverpool.ac.uk. 


\section{Appendix A. Sample script for each elicitation task.}

\section{Auxiliary CAN, WILL, and DOES: Declaratives}

Experimenter (E): We are going to play a game about opposites. I have a picture and you have a picture that shows the opposite to my picture. I'm going to say what is happening in my picture and you have to say what is happening in your picture. Okay?

\section{Training Phase}

Give child (C) his/her card, look at own card.

E: Okay, let's start. In my picture the boy is going to the park. What about your picture? In your picture the boy isn't going to the park. Can you say that?

C: Response (Target: "The boy isn't going to the park")

If inappropriate/no response: E: You have to say "The boy isn't going to the park." Can you say that? "The boy ... "

C: Response

Repeat for Training ltems 2-4.

Test Phase

E: In my picture the zebra doesn't shut the gate. What about your picture? In your picture ...

C: Response (Target: "The zebra shuts the gate")

If inappropriate/no response: E: You have to say what's happening in your picture, remember. So, in my picture the zebra doesn't shut the gate. But in your picture ...

If still inappropriate/no response: E: Can you tell me what's happening in your picture? In my picture the zebra doesn't shut the gate. In your picture the zebra ...

If still inappropriate/no response: E: In your picture the zebra shuts the gate. Can you say that?

Repeat for Test ltems 2-18.

2. Auxiliary CAN, WILL, and DOES: Questions

E: I have two friends here. Here is Piglet. Piglet likes to play, but he is very shy and will only play in secret. So he's going to play behind this screen.

Place Piglet behind screen.

E: My other friend is the pony. Piglet doesn't mind the pony watching him play.

Place the pony so it can see Piglet.

E: Now, Piglet's going to play, and we have to ask the pony questions about what Piglet is doing. But the pony doesn't talk to grown-ups, only to children, so you'll have to ask him the questions. Okay?

Training Phase

Mother makes Piglet move behind screen.

E: Oh no. Somebody is kissing Piglet. I think it's the doctor. Ask the pony if the doctor is kissing Piglet.

C: Response (Target: "Is the doctor kissing Piglet?")

If appropriate response: Play prerecorded pony response.

If inappropriate/no response: E: You have to ask the pony the question because he won't answer me. Can you say to the pony "Is the doctor kissing Piglet?"

If inappropriate/no response: E: Can you ask him? Can you say "Is the doctor kissing Piglet?"

Repeat for Training ltems 2-4.

Test Phase

E: I think Piglet can move the goal. Ask the pony if Piglet can move the goal.

C: Response (Target: "Can Piglet move the goal?")

If appropriate response: Play prerecorded pony response.

If inappropriate/no response: $\mathrm{E}$ : Remember, you have to ask the pony because he won't talk to adults. Ask the pony if Piglet can move the goal.

If inappropriate/no response: E: You have to ask him. Ask the pony if Piglet can move the goal.

If inappropriate/no response: E: You have to say "Can Piglet move the goal?"

Repeat for Test ltems 2-18. 


\section{Appendix B. Coding criteria.}

\begin{tabular}{|c|c|c|c|c|c|c|c|}
\hline \multirow[b]{2}{*}{ Form } & \multirow[b]{2}{*}{ Inclusion criteria } & \multirow[b]{2}{*}{ Correct responses } & \multicolumn{5}{|c|}{ Errors } \\
\hline & & & Substitution & Omission & Uninversion & Double marking & Agreement \\
\hline & $\begin{array}{l}\text { Must include either } \\
\text { subject or verb. } \\
\text { Unclear material accepted if } \\
\text { auxiliary and subject or } \\
\text { verb are unambiguous. }\end{array}$ & $\begin{array}{l}\text { Target auxiliary and subject } \\
\text { or verb required. Pronominal } \\
\text { subjects accepted. Verb } \\
\text { replacements accepted. }\end{array}$ & $\begin{array}{l}\text { Use of an alternative } \\
\text { auxiliary (progressives } \\
\text { excluded). }\end{array}$ & Auxiliary omitted. & $\begin{array}{l}\text { Auxiliary in declarative } \\
\text { position, or use of } \\
3 S \text { verb form where } \\
\text { inverted DO required. }\end{array}$ & $\begin{array}{l}\text { Use of two auxiliaries, } \\
\text { or auxiliary alongside } \\
\text { 3S verb marking where } \\
\text { one auxiliary is form of } \\
\text { target auxiliary. }\end{array}$ & $\begin{array}{l}\text { Use of incorrect } \\
\text { person marked } \\
\text { form of DO, use } \\
\text { of } 3 S \text { verb with } \\
\text { singular subject. }\end{array}$ \\
\hline Declaratives & & $\begin{array}{l}\text { Use of correctly inflected third } \\
\text { person lexical verb instead } \\
\text { of does accepted as a } \\
\text { correct response. }\end{array}$ & $\begin{array}{l}\text { "Piglet can (= will) } \\
\text { ride a bike" }\end{array}$ & $\begin{array}{l}\text { "Piglet not push } \\
\text { the kennel/Piglet } \\
\text { push the kennel" }\end{array}$ & & $\begin{array}{l}\text { "Doesn't washes } \\
\text { the spoon" }\end{array}$ & "Do reach the fork" \\
\hline Questions & $\begin{array}{l}\text { Must have rising intonation } \\
\text { if declarative word order. } \\
\text { Must include subject }\end{array}$ & & $\begin{array}{l}\text { "Can (= will) Piglet } \\
\text { ride a bike?" }\end{array}$ & $\begin{array}{l}\text { "Piglet ride a } \\
\text { bike?" }\end{array}$ & $\begin{array}{l}\text { "Piglet can wash the } \\
\text { eggs?/Piglet washes } \\
\text { the eggs?" }\end{array}$ & $\begin{array}{l}\text { "Will Piglet will } \\
\text { bounce the sponge?" }\end{array}$ & $\begin{array}{l}\text { "Do Piglet break } \\
\text { the chair?" }\end{array}$ \\
\hline
\end{tabular}

Note. Responses that did not meet the general inclusion criteria were coded as nontarget responses. $3 S=$ third person singular. 